CENTRO UNIVERSITÁRIO FEI

SANDRO AUGUSTO HIRAI

COMO O PROCESSO DE ELICITAÇÃO DE PREFERÊNCIAS INFLUENCIA A ACEITAÇÃO DE RECOMENDAÇÕES DE INTELIGÊNCIA ARTIFICIAL 
SANDRO AUGUSTO HIRAI

\section{COMO O PROCESSO DE ELICITAÇÃO DE PREFERÊNCIAS INFLUENCIA A ACEITAÇÃO DE RECOMENDAÇÕES DE INTELIGÊNCIA ARTIFICIAL}

Trabalho de Defesa de Dissertação de Mestrado apresentada ao Centro Universitário FEI, como parte dos requisitos necessários para obtenção do título de Mestre em Administração de Empresas. Orientado pelo Prof. Dr. José Mauro da Costa Hernandez. 
Hirai, Sandro Augusto.

COMO O PROCESSO DE ELICITAÇÃO DE PREFERÊNCIAS

INFLUENCIA A ACEITAÇÃO DE RECOMENDAÇÕES DE

INTELIGÊNCIA ARTIFICIAL / Sandro Augusto Hirai. São Paulo, 2020. $87 \mathrm{p}$.

Dissertação - Centro Universitário FEI.

Orientador: Prof. Dr. José Mauro da Costa Hernandez.

1. Processo de Elicitação de Preferências. 2. Aceitação de Algoritmo. 3. Sistema de Recomendação. I. Hernandez, José Mauro da Costa, orient. II. Título.

Elaborada pelo sistema de geração automática de ficha catalográfica da FEI com os dados fornecidos pelo(a) autor(a). 
Sandro Augusto Hirai

centro

universitário

\section{APRESENTAÇÃO DE DISSERTAÇÃO \\ ATA DA BANCA JULGADORA}

Programa de Pós-Graduação Stricto Sensu em Administração

MESTRADO PPGA-10

Aluno: Sandro Augusto Hirai

Matrícula: $321802-1$

Título do Trabalho: Como o processo de Elicitação de Preferências Influencia a Aceitação de Recomendações de Inteligência Artificial?

Área de Concentração: Gestão da Inovação

Orientador: Prof. Dr. José Mauro Da Costa Hernandez

Data da realização da defesa: $22 / 12 / 2020$.

Avaliação da Banca Examinadora:

ORIGINAL ASSINADA

São Paulo, $22 / 12 / 2020$.

MEMBROS DA BANCA EXAMINADORA

Prof. Dr. José Mauro Da Costa Hernandez Ass.

Profa. Dra. Melby Karina Zuniga Huertas

Profa. Dra. Tania Pereira Christopoulos

Ass.

Ass.:

A Banca Julgadora acima-assinada atribuiu ao aluno o seguinte resultado:

APROVADO $\square \quad$ REPROVADO $\square$

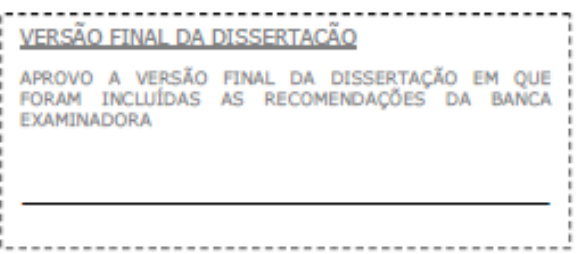

Aprovação do Coordenador do Programa de Pós-graduação

Prof. Dr. Henrique Machado Barros 
Esta dissertação é dedicada à minha família que com muita luta e determinação, saímos vitoriosos em mais um desafio. 


\section{AGRADECIMENTOS}

Gostaria de agradecer a Deus pela oportunidade de concretizar mais um sonho, aos meus pais Yukio e Hiroko por me incentivarem a perseverar nas dificuldades, à minha família, Fabiana, Enzo e Giovanna, por estarem ao meu lado durante o mestrado e por compreenderem os momentos ausentes em família.

Agradeço o meu orientador Jose Mauro por aceitar o desafio de conduzir esta pesquisa e pelos ensinamentos, orientações e paciência nos momentos críticos. Agradeço também as professoras Melby e Tania por seus valiosos comentários e recomendações e por fim um agradecimento especial a todo corpo docente do Programa de Pós-Graduação em Administração da FEI, colegas de classe e funcionários pelo apoio e carinho expressados durante o curso. 
"It is not the critic who counts; not the man who points out how the strong man stumbles, or where the doer of deeds could have done them better. The credit belongs to the man who is actually in the arena, whose face is marred by dust and sweat and blood; who strives valiantly; who errs, who comes short again and again, because there is no effort without error and shortcoming; but who does actually strive to do the deeds; who knows great enthusiasms, the great devotions; who spends himself in a worthy cause; who at the best knows in the end the triumph of high achievement, and who at the worst, if he fails, at least fails while daring greatly, so that his place shall never be with those cold and timid souls who neither know victory nor defeat."

Theodore Roosevelt. 


\section{RESUMO}

A adoção ou a aversão à uma recomendação proveniente de um algoritmo é um tema que desperta interesse nos pesquisadores de campos de conhecimentos tão diversos como inteligência artificial, sistemas de informação, marketing ou comportamento do consumidor. No entanto, poucos trabalhos empíricos sobre o comportamento dos indivíduos em relação aos algoritmos estão disponíveis na literatura e pouco se sabe sobre os motivos subjetivos que levam o consumidor a adotar ou rejeitar uma recomendação feita por um agente de inteligência artificial. Estudos apontam que a precisão do algoritmo poderia influenciar a aceitação, diferentes trabalhos indicam que o tipo de tarefa em que se enquadra a recomendação teria influência na aceitação. Porém estes estudos apresentaram uma certa ambiguidade nas conclusões e outros motivos poderiam levar a aceitação da recomendação. A exemplo de outras pesquisas, que apontam para a incompreensão da lógica interna do algoritmo que provocaria a rejeição da recomendação do algoritmo. Por outro lado, existe uma interação inicial entre o algoritmo e o usuário chamado de processo de elicitação de preferências (PEP), estágio pela qual o usuário informa suas preferências e necessidades utilizadas pelo algoritmo na preparação da recomendação, que pode influenciar a aceitação da recomendação. Estudos indicam que este processo de interação influencia a satisfação com a recomendação porque proporciona um sentimento de transparência e relevância na formulação da recomendação, cria uma expectativa de qualidade na recomendação e pode ajudar na compreensão da lógica interna do algoritmo. No entanto foram encontrados poucos experimentos que analisaram o PEP com a satisfação da recomendação e carece de novos estudos empíricos. Outro tema encontrado na literatura mas também pouco explorado referese a influência do conhecimento subjetivo sobre o domínio da recomendação na satisfação do usuário. Então o PEP influencia na satisfação com a recomendação? O conhecimento subjetivo do usuário atenua ou acentua a aceitação da recomendação? Dessa forma, os principais objetivos deste trabalho são estudar se o processo de elicitação de preferências (PEP) influencia a satisfação com a recomendação bem como se o conhecimento do indivíduo sobre o domínio da recomendação exerce uma influência na satisfação do consumidor. Para atingir estes objetivos, realizou-se um experimento exploratório que manipulou distintos PEPs, considerando o nível de conhecimento subjetivo sobre o domínio da recomendação. A análise do PEP isoladamente demonstrou efeitos marginalmente siginificativos, entretanto quando analisado em conjunto com o conhecimento sobre o domínio, os resultados indicam diferenças significativas na satisfação. Assim foi possível verificar a influência do PEP com o 
conhecimento subjetivo na satisfação do usuário. Portanto esta pesquisa exploratória contribuiu para a literatura não somente com novas aprendizagens sobre o processo de elicitação de preferências per se, mas também com novos estudos envolvendo o PEP e o conhecimento subjetivo sobre o domínio da recomendação. Ao mesmo tempo a pesquisa colabora com a prática no mundo corporativo, no sentido de trazer novas ideias para que empresas aprimorem seus PEPs em funcionamento ou desenvolvam novas estratégias que proporcionem uma maior satisfação para os consumidores.

Palavras-chave: Processo de Elicitação de Preferências. Aceitação de Algoritmo. Sistema de Recomendação. 


\begin{abstract}
The adoption or aversion to a recommendation from an algorithm is a topic that arouses interest in researchers from fields as diverse as artificial intelligence, information systems, marketing, or consumer behavior. However, few empirical studies on the behavior of individuals in relation to algorithms are available in the literature and little is known about the subjective reasons that lead consumers to adopt or reject a recommendation made by an artificial intelligence agent. Studies indicate that the accuracy of the algorithm could influence acceptance, different studies indicate that the type of task in which the recommendation fits would influence acceptance. However, these studies presented a certain ambiguity in the conclusions and other reasons could lead to the acceptance of the recommendation. Like others researches that point to the misunderstanding of the internal logic of the algorithm, it would provoke the rejection of the algorithm's recommendation. On the other hand, there is an initial interaction between the algorithm and the user called the preferences elicitation process (PEP), a stage by which the user informs his preferences and needs used by the algorithm in preparing the recommendation, which can influence the acceptance of the recommendation. Studies indicate that this interaction process influences satisfaction with the recommendation because it provides a feeling of transparency and relevance in the formulation of the recommendation, creates an expectation of quality in the recommendation and can help in understanding the internal logic of the algorithm. However, few experiments were found that analyzed the PEP with the satisfaction of the recommendation and lacks further empirical studies. Another topic found in the literature, but also little explored, refers to the influence of subjective knowledge on the domain of recommendation on user satisfaction. So, does PEP influence satisfaction with the recommendation? Does the user's subjective knowledge attenuate or enhance the acceptance of the recommendation? Thus, the main objectives of this work are to study whether the preferences elicitation process (PEP) influences satisfaction with the recommendation as well as whether the individual's knowledge of the recommendation domain influences consumer satisfaction. To achieve these objectives, an exploratory experiment was carried out that manipulated different PEPs, considering the level of subjective knowledge about the recommendation domain. The analysis of the PEP alone showed marginally significant effects, however when analyzed together with domain knowledge, the results indicate significant differences in satisfaction. Thus, it was possible to verify the influence of PEP along with subjective knowledge on user satisfaction. Therefore,
\end{abstract}


this exploratory research has contributed to the literature not only with new learning about the preferences elicitation process per se, but also with new studies involving the PEP and subjective knowledge about the recommendation domain. At the same time, the research collaborates with the practice in the corporate world, to bring new ideas for companies to improve their PEPs in operation or develop new strategies that provide greater satisfaction to consumers.

Keywords: Preference Elicitation Process. Algorithm Adoption. Recommendation System. 


\section{LISTA DE ILUSTRAÇÕES}

Quadro 1 - Principais artigos que nortearam o presente trabalho .........................................28

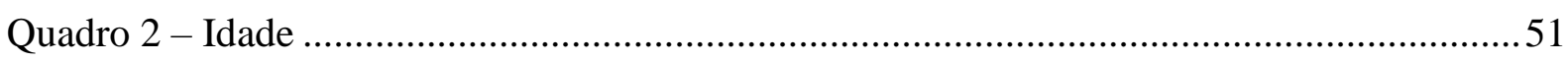

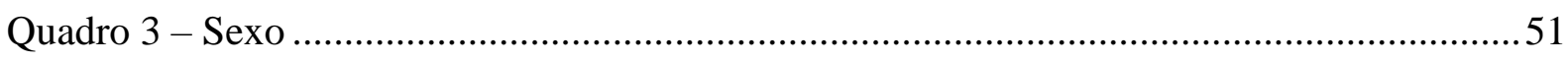

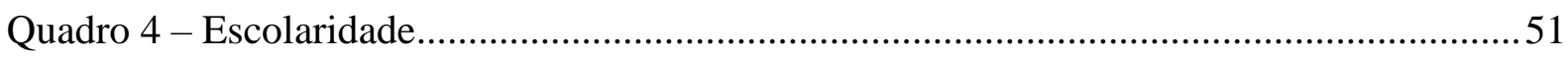

Figura 1 - Preferências e intenção de compra por tipo de elicitação inicial de preferências ..52

Figura 2 - Preferências por tipo de elicitação inicial de preferências e por nível de

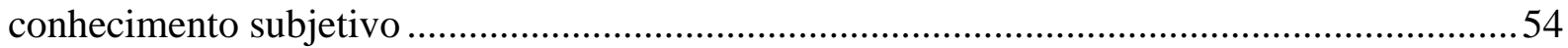

Figura 3 - Preferências por tipo de elicitação inicial de preferências e por nível de conhecimento subjetivo 


\section{SUMÁRIO}

1 INTRODUÇÃO ......................................................................................................................... 14

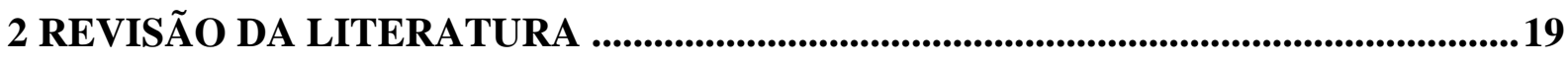

2.1 CONCEITOS INICIAIS SOBRE INTELIGÊNCIA ARTIFICIAL, INTERNET DAS

COISAS E ALGORITMOS DE RECOMENDAÇÃO ....................................................... 19

2.2 ARTIGOS RECENTES SOBRE ACEITAÇÃO DE ALGORITMOS E O PROCESSO DE

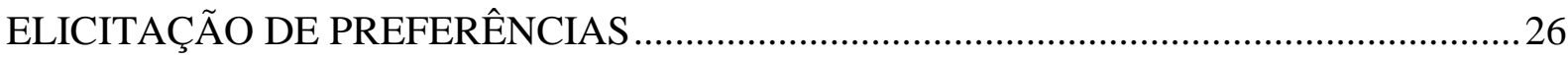

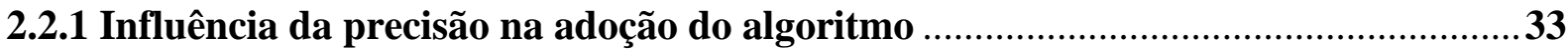

2.2.2 Influência do tipo de tarefa na adoção do algoritmo................................................34

2.2.3 Influência do desconhecimento da lógica interna do algoritmo ................................36

2.2.4 Influência do processo de elicitação de preferências na adoção do algoritmo..........37

2.2.5 Influência do conhecimento prévio sobre o domínio da recomendação ...................39

2.2.6 Traços individuais e o processo de elicitação de preferências .................................41

3 LACUNAS E OBJETIVOS ....................................................................................................44

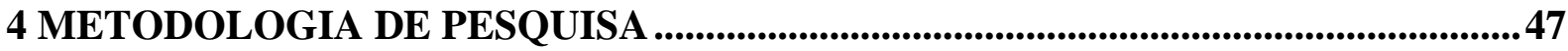

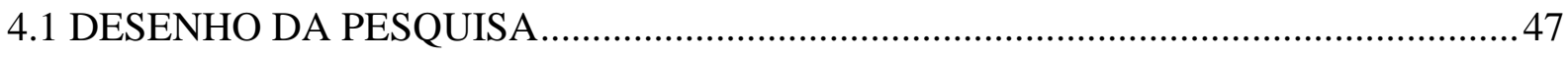

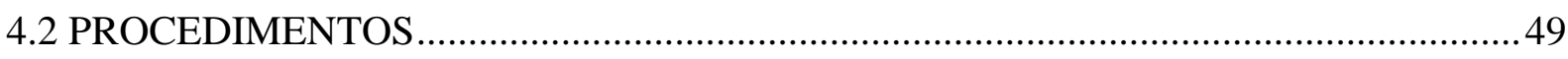

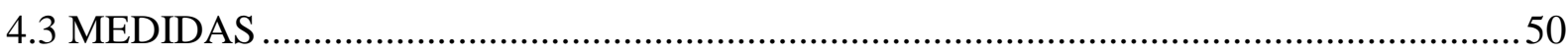

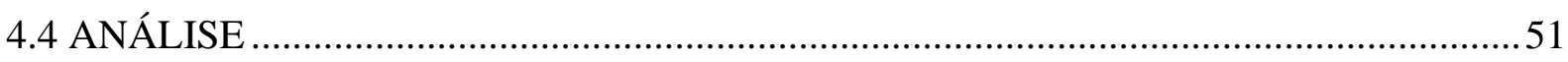

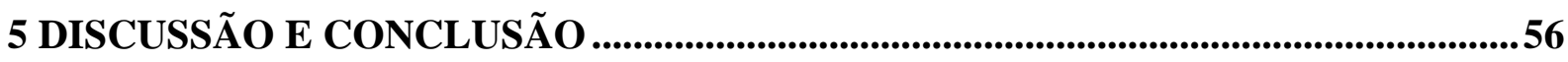

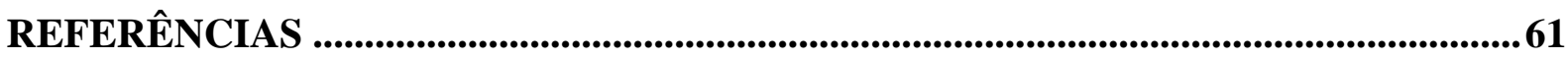

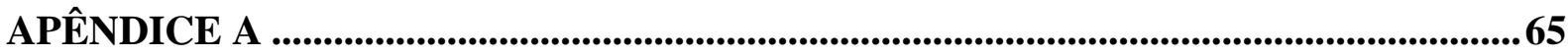

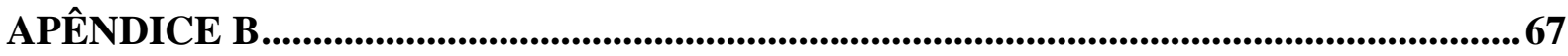

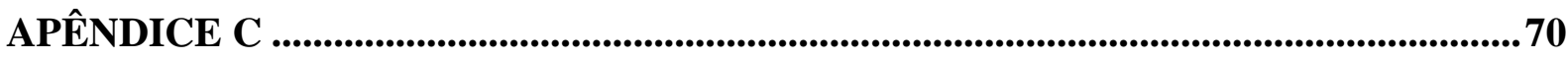

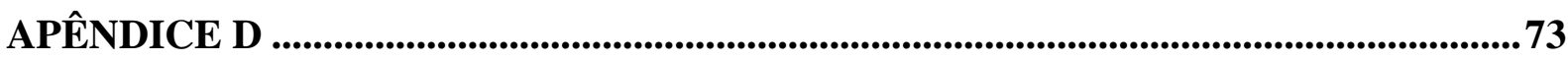

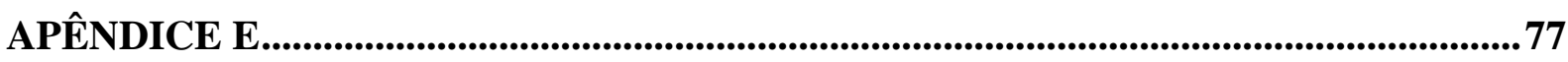

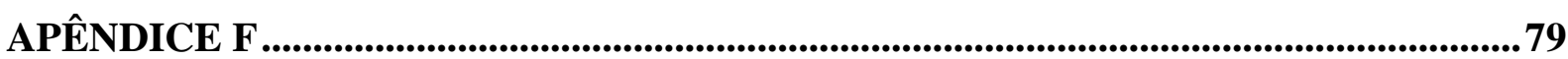




\section{INTRODUÇÃO}

Nos últimos anos, o desenvolvimento de novas tecnologias foi extremamente acentuado e sistemas avançados de recomendações estão cada vez mais presentes na vida das pessoas, fornecendo dados e informações que auxiliam a tomada de decisões.

De fato, há uma infinidade de aplicativos que oferecem recomendações para as atividades mais rotineiras dos indivíduos que vão desde aplicativos que auxiliam no deslocamento de um ponto a outro na cidade, apresentando as rotas com menor tempo de deslocamento (DOVE; HILL, 2020), passando por algoritmos de recomendação em sites de comércio eletrônico indicando livros, vinhos e outros produtos (RICCI; SHAPIRA; ROKACH, 2015), recomendação de filmes em serviços de streaming (RICCI; SHAPIRA; ROKACH, 2015), assistentes de voz que auxiliam a busca de conteúdos e compras de itens para o consumo diário (MCCAFFREY et al., 2018) e chegam a dispositivos interconectados nos lares como ar condicionado, termostato, câmera de segurança e fechaduras eletrônicas que tornam a casa mais "inteligente” (PRATA, 2019).

As aplicações acima são apenas alguns poucos exemplos de como os algoritmos de recomendação evoluíram rapidamente, em grande parte devido aos avanços da tecnologia de processamento de dados, ao desenvolvimento da inteligência artificial e à gigantesca quantidade de dados disponíveis para o uso em recomendações e tomada de decisões (HOSANAGAR, 2019).

As denominações "sistemas de recomendação", "agentes de recomendação" ou simplesmente "algoritmos" são terminologias comumente utilizadas em pesquisas sobre adoção de recomendação proveniente de uma determinada tecnologia e não de um ser humano. De toda forma um sistema de recomendação ou agente de recomendação necessita de um algoritmo para tratar a informação e criar a recomendação (PORTUGAL; ALENCAR; COWAN, 2018), contudo, será utilizado somente o termo "algoritmo" neste trabalho de pesquisa para efeito de simplificação de terminologias. Este termo parece ser mais abrangente que as demais terminologias pois o algoritmo pode ser utilizado em qualquer plataforma tecnológica, envolvendo desde sites de comércio eletrônico a veículos autônomos.

Portanto, uma vez que os algoritmos de recomendação influenciam direta ou indiretamente a vida cotidiana das pessoas, o seu estudo tem chamado a atenção dos pesquisadores da área de marketing, principalmente no que tange ao comportamento dos indivíduos com as recomendações apresentadas pelos algoritmos. 
Ao longo dos anos, as pesquisas sobre algoritmo de recomendação se expandiram para o estudo de aplicativos em aparelhos celulares e, ultimamente, surgiram pesquisas investigando a aceitação de algoritmos de recomendação em novas plataformas tecnológicas como carros autônomos bem como novos campos de atuação, a exemplo da medicina.

De forma geral, as recentes pesquisas sobre a aceitação de algoritmos de recomendação indicam caminhos conflitantes com respeito ao comportamento do consumidor: se, por um lado, uma linha de pesquisa demonstra que os indivíduos aceitam a recomendação (ALEXANDER; BLINDER; ZAK, 2018; LOGG, 2017; LOGG; MINSON; MOORE, 2019), por outro lado, uma outra linha de pesquisa sugere que os indivíduos são resistentes à recomendação de algoritmos (CASTELO; BOS; LEHMANN, 2019; DIETVORST; SIMMONS; MASSEY, 2015a, 2015b).

Logg, Minson e Moore (2019) realizaram um trabalho para entender se haveria uma diferença de confiança entre uma recomendação feita por uma pessoa e uma recomendação feita por um algoritmo e descobriram que, caso a mesma recomendação fosse dada por um algoritmo ou por uma pessoa, a confiança seria maior com o algoritmo. Os indivíduos estudados demonstraram essa preferência em situações que envolviam eventos geopolíticos, popularidade de músicas e atratividade romântica entre casais.

Corroborando esta pesquisa, Germann e Merkle (2020) estudaram a confiança em algoritmos de recomendação em investimentos financeiros e constataram que os respondentes passaram a aceitar melhor o algoritmo de recomendação quando eles perceberam que os resultados apresentados pelos algoritmos eram mais eficientes que os resultados apresentados por pessoas, os gestores responsáveis pela aplicação financeira.

Entretanto, recentes pesquisas concluíram que os indivíduos podem desenvolver uma aversão à algoritmos de recomendação quando eles percebem que os algoritmos apresentam erros e, assim, deixariam de utilizá-los (DIETVORST; SIMMONS; MASSEY, 2015a). De forma análoga, Yeomans et al (2019) perceberam em sua pesquisa que, apesar dos algoritmos serem mais precisos e eficazes, alguns indivíduos preferiram recomendações de pessoas conhecidas, em oposição ao algoritmo. Yeomans et al (2019) concluíram que as pessoas são levadas a escolher recomendações de pessoas ao invés de recomendações de algoritmos por não entenderem como um algoritmo pode produzir a recomendação.

Outros estudiosos, contudo, ponderam que a aceitação da recomendação de um algoritmo no processo decisório pode depender do contexto em que se encontra a decisão com respeito às características hedônicas ou utilitárias relevantes para a tomada de decisão bem 
como à percepção do usuário de que o algoritmo possui competência e capacidade para ajudálo na melhor escolha (LONGONI; CIAN, 2020).

Os estudos citados anteriormente não foram totalmente conclusivos sobre os motivos que levam os consumidores a seguir ou não as recomendações de um algoritmo. De toda forma, reconhecem que os algoritmos de recomendação estão presentes na vida cotidiana das pessoas, sejam em decisões simples ou em decisões complexas, e, portanto, é importante refletir sobre os motivos que facilitam a sua adoção ou, ao contrário, ponderar sobre as razões que provocam sua aversão.

As visões discrepantes dos pesquisadores citados e os questionamentos sem respostas incentivaram a investigação de potenciais lacunas na literatura ainda não avaliadas. Nesse sentido, há uma importante etapa de interação entre o usuário e algoritmo que foi pouco explorada pelos pesquisadores e desenvolve uma influência na satisfação do usuário com a recomendação. $\mathrm{O}$ algoritmo necessita de dados para oferecer uma recomendação e, portanto, há uma comunicação inicial entre o algoritmo e o usuário com o propósito de obter suas preferências e gostos. Este contato entre o algoritmo e o usuário é chamado de processo de elicitação de preferência (PEP), etapa fundamental que guia o algoritmo na conclusão da melhor recomendação (RICCI; SHAPIRA; ROKACH, 2015)

Pesquisas sobre o PEP (GRETZEL; FESENMAIER, 2005) sugerem que este estágio inicial de interação cria uma expectativa de que o algoritmo proporcionará uma recomendação com qualidade devido a transmissão transparente e relevante das necessidades do usuário. É possível que esta percepção de qualidade gerada pelo PEP possa ser mais relevante e superar as questões de precisão, tipo de tarefas ou a incompreensão da lógica interna do algoritmo, apontados como fatores que influenciaram negativamente na satisfação do usuário com a recomendação do algoritmo. No entanto, um levantamento realizado por pesquisadores apontaram que o PEP é um processo pouco investigado porque pressupõe-se que o algoritmo já possui todas as informações necessárias sobre as preferências do usuário e assim, seu estudo é muitas vezes negligenciado na literatura (JUGOVAC; JANNACH; DORTMUND, 2017).

As recomendações de algoritmos estão presentes na vida cotidiana das pessoas e dessa forma é possível inferir que há indivíduos com pouco conhecimento sobre a área em que a recomendação é aplicada, mas por outro lado, existem indivíduos experientes com conhecimentos aprofundados sobre os domínios da recomendação. Pesquisadores apontaram que esse conhecimento subjetivo que o indivíduo possui sobre o domínio da recomendação pode influenciar a satisfação com o algoritmo. Porém assim como o processo de elicitação de 
preferências, existem poucos experimentos que investigaram o conhecimento subjetivo sobre o domínio da recomendação.

Com efeito, a revisão da literatura encontrou poucos estudos relacionados aos temas acima e assim sendo, incentivou o desenvolvimento desta pesquisa exploratória cujo objetivo geral é estudar o processo de elicitação de preferências (PEP) juntamente com o conhecimento do usuário sobre o domínio da recomendação. Os resultados encontrados foram satisfatórios considerando a natureza exploratória desta pesquisa e observou-se a influência do PEP na satisfação do usuário bem como a ação do conhecimento subjetivo.

Esta pesquisa contribui para a literatura com novos experimentos e considerações pouco sondadas em pesquisas anteriores e expandiu os estudos sobre o PEP. Por exemplo, apesar da semelhança entre esta pesquisa com o trabalho de Knijnenburg, Reijmer e Willemsen (2011), o presente estudo se diferenciou na forma de manipulação dos PEPs e no estudo de recomendações de produtos com características subjetivas ou hedônicas. Outrossim, complementando estudos anteriores, esta pesquisa mediu também o conhecimento subjetivo sobre o domínio da recomendação e o considerou na análise dos resultados. Concomitantemente, de certa maneira, a revisão da literatura realizada para o desenvolvimento deste trabalho pode ser considerada igualmente como uma contribuição para literatura, pois levantou novas pesquisas que complementam a pesquisa anterior de Verruk e Nique (2017).

A pesquisa colabora também para a prática do processo de elicitação de preferências com novas ideias para a resolução de eventuais problemas com a aceitação de recomendações. De fato, Longoni e Cian (2020) relataram que o Walmart dos EUA possui problemas de aceitação com a recomendação de bebidas alcoólicas em seu site de comércio eletrônico. Esta pesquisa pode contribuir para empresas como o Walmart no sentido de encontrar caminhos para a aceitação de recomendações desses produtos, uma vez que esta pesquisa demonstrou a possibilidade de aceitação de recomendações de cervejas especiais, um produto de natureza hedônica.

A próxima sessão descreve a revisão da literatura sobre o processo de elicitação de preferência e aceitação de algoritmos, indica as lacunas encontradas na revisão dos artigos e apresenta os objetivos da pesquisa. A sessão detalha também as principais técnicas utilizadas pelos algoritmos na criação de uma recomendação, conceitos iniciais sobre inteligência artificial e internet-das-coisas pois todos estes conceitos estão interrelacionados de alguma forma e a compreensão geral sobre estes temas facilitarão a leitura da pesquisa. 
Na sessão subsequente são descritos a metodologia utilizada, o desenho de pesquisa, os procedimentos do experimento, as medidas e análises descritivas. Já os resultados e suas conclusões são apresentados na parte final da pesquisa com a expectativa de estimular o desenvolvimento de novos estudos sobre o comportamento do consumidor frente ao processo de elicitação de preferências, e assim, poder contribuir com a geração de novos conhecimentos para a literatura. Ao mesmo tempo, espera-se que esta pesquisa possa ajudar empresas e órgãos governamentais a repensarem suas práticas atuais e adotarem novas estratégias com o processo de elicitação de preferência que possam melhorar a satisfação dos usuários com as recomendações geradas pelos algoritmos. 


\section{REVISÃO DA LITERATURA}

A revisão da literatura tomou como base artigos recentes encontrados na base de dados do "Web of Science" e "Google Scholar". Além dos artigos relacionados com o tema desta pesquisa, serão introduzidos conceitos básicos sobre algoritmo e suas principais técnicas, inteligência artificial, internet das coisas e "machine learning" para facilitar a compreensão dos termos utilizados nesta pesquisa exploratória.

\subsection{CONCEITOS INICIAIS SOBRE INTELIGÊNCIA ARTIFICIAL, INTERNET DAS COISAS E ALGORITMOS DE RECOMENDAÇÃO}

Como este trabalho de pesquisa analisará o comportamento do consumidor frente ao algoritmo de recomendação, a apresentação de alguns conceitos básicos sobre algoritmo, inteligência artificial e Internet das Coisas (IoT) se torna interessante para proporcionar uma visão genérica de como um algoritmo trabalha para chegar na recomendação e como os recentes avanços na tecnologia fomentaram a sua aplicação cada vez mais presente nos dias atuais.

Um algoritmo pode ser definido como um roteiro de instruções lógicas e matemáticas que filtram e analisam um grande volume de dados e produzem conclusões no direcionamento de ações para o alcance do objetivo final (LOGG; MINSONA; MOOREB, 2019). Outros pesquisadores, por sua vez, definem o algoritmo como um conjunto de instruções que seguem uma determinada sequência lógica para finalizar um objetivo (HOSANAGAR, 2019). Para outros, ele simplesmente pode ser qualquer regra automatizada que processa dados (GERMANN; MERKLE, 2020).

Marr (2016), entretanto, descreve Inteligência Artificial essencialmente como um conceito abrangente em que dispositivos podem realizar tarefas autônomas independentes da interferência de humanos e, assim, são considerados “inteligentes". De fato, a Inteligência Artificial pode ser classificada em dois grandes grupos: Aplicada e Geral. A Inteligência Artificial Aplicada são as aplicações mais fáceis de serem encontradas como: softwares de venda e compra de ações, recomendações de compra de produtos ou condução autônoma de veículos. A Inteligência Artificial Geral parte do princípio de que o dispositivo pode realizar qualquer tarefa e pode aprender de forma independente com a utilização de uma base dados. 
A Internet das Coisas (IoT), por outro lado, trata do conjunto de dispositivos eletrônicos conectados na internet e capazes de coletar dados enviados através da internet. Ela está cada vez mais incorporada nos equipamentos eletrônicos comumente encontrados dentro e fora de casa, sendo utilizados em atividades que envolvem compras, entretenimento, transporte e bem-estar (HOFFMAN; NOVAK, 2018).

Este é o conceito normalmente entendido pelas pessoas, mas IoT tem uma aplicação muito mais ampla. Com efeito, um dos principais propósitos de IoT é possibilitar a criação de ambientes e espaços inteligentes em que dispositivos autoconscientes possam melhorar o controle e gestão de energia, mobilidade, clima, alimentos e saúde entre outros campos de atuação em nossa sociedade. Assim temos "Industrial IoT", que são a extensão do uso de IoT em aplicações industriais; "Smart Cities" que são o uso de IoT na gestão dos recursos das cidades; "Energy IoT", que são o uso de IoT no controle da geração e distribuição de energia; o uso de IoT na gestão da saúde das pessoas, é chamado de "Internet of Health Care Things (IoHT)"; e, finalmente, há as aplicações de IoT na Agricultura para melhorar sua produtividade (PERWEJ et al., 2019).

Deste modo, a Internet das Coisas (IoT) coleta uma grande quantidade de dados que um ser humano sozinho não poderia processar e, dessa forma, a Inteligência Artificial (IA) se torna uma opção real para o tratamento dessa quantidade de informações. A IA, no entanto, nem sempre sabe o sentido ou propósito de determinado conhecimento e assim se origina o processo de aprendizado pelo qual a IA analisa os dados para "aprender" a interpretá-los. Espera-se, assim, que o uso da IA possibilitará novas formas de processar os dados, de interpretar conexões que não estavam disponíveis e oferecerá aplicações interessantes em áreas como saúde, marketing, transporte e finanças (DOBRESCU; DOBRESCU, 2017).

O conceito de "Machine Learning", por sua vez, refere-se a uma aplicação da Inteligência Artificial Geral na qual os dispositivos aprendem uma função ou ação por meio da análise dos dados disponíveis. O desenvolvimento de redes neurais foi uma evolução importante que fez com que os computadores pensassem, interpretassem e classificassem informações como os seres humanos (MARR, 2016). O "Machine Learning" (ML) usa computadores para simular o aprendizado humano e permite que computadores identifiquem e adquiram conhecimento do mundo real para melhorar seu desempenho em algumas tarefas com base nesse novo conhecimento.

De fato, a aprendizagem é o processo de aquisição de conhecimento e os seres humanos naturalmente aprendem com a experiência por causa de sua capacidade de 
raciocinar. Os computadores, contudo, não aprendem por raciocínio, e sim com algoritmos (PORTUGAL; ALENCAR; COWAN, 2018).

No passado, os desenvolvedores de algoritmos entrevistavam especialistas para identificar em detalhes quais eram as ações necessárias para realizar uma determinada tarefa e assim programavam o algoritmo para seguir a mesma sequência de ações na direção da conclusão da tarefa. Entretanto, com o avanço do "Machine Learning", esse procedimento e a forma de organizar internamente o algoritmo não são mais necessários. Os dispositivos são programados para interpretarem e aprenderem com a grande quantidade de dados disponíveis e assim realizar a atividade de forma autônoma e inteligente (HOSANAGAR, 2019).

As primeiras pesquisas sobre algoritmos de recomendação surgiram a partir da segunda metade da década de 90 e analisaram técnicas de filtragem colaborativa como mecanismo de recomendação (PORTUGAL; ALENCAR; COWAN, 2018; RICCI; SHAPIRA; ROKACH, 2015).

De forma simples, é possível dizer que os algoritmos de recomendação apresentam informações individuais como listas de classificação de itens personalizados com o objetivo de prever qual a melhor opção baseada nas preferências do usuário (RICCI; SHAPIRA; ROKACH, 2015). Dessa forma, o algoritmo de recomendação reúne dados de preferências das pessoas ou tenta inferir sua propensão ao uso considerando a navegação realizada em uma página de produtos na internet, por exemplo.

Trata-se de uma forma eficiente de administrar o volume de informações existentes para os indivíduos e pode indicar itens desconhecidos que não seriam descobertos sem sua existência (RICCI; SHAPIRA; ROKACH, 2015).

Os algoritmos de recomendação são utilizados na maioria dos sites de compra de produtos ou serviços (Amazon, eBay, Tripadvisor, Booking), plataformas de entretenimento (YouTube, Netflix, Spotify, Last.fm), mídias sociais (LinkedIn, Facebook), entre outros. De forma geral, as empresas implementaram algoritmos de recomendação em suas páginas web como uma ferramenta de busca de produtos para os seus consumidores (RICCI; SHAPIRA; ROKACH, 2015).

Na perspectiva das empresas, os algoritmos de recomendação são implementados para finalidades distintas, como por exemplo, aumentar o número de produtos vendidos, a satisfação e fidelidade do usuário com produtos de seu interesse e entender melhor o cliente por meio de suas preferências e comportamento de compras. A perspectiva do usuário, entretanto, é diferente. Ricci, Shapira e Rokach (2015) propõem que o indivíduo utilize os 
algoritmos de recomendação como forma de expressão por meio de comentários sobre a sua experiência e notas de avaliação.

É possível, porém, que alguns usuários manipulem os algoritmos de recomendação com o único propósito de influenciar a compra de um determinado item sem descrever a verdadeira experiência, o que caracteriza manipulação de informações com fins maliciosos alimentando os algoritmos com viés de informação (XIAO; BENBASAT, 2018).

Para efeito de ilustração, é interessante explicar a lógica de um algoritmo simples de recomendação, como a recomendação de filmes populares. Uma vez que não existem informações prévias sobre as preferências do usuário, um filme conhecido por muitas pessoas e que chame a atenção de várias pessoas pode chamar a atenção de um assinante genérico, ou, no mínimo, este filme terá probabilidade maior de reconhecimento se comparado a outro filme escolhido aleatoriamente. Assim, é possível prever que a popularidade dos filmes ditos conhecidos ou populares seja relativamente mais alta para um assinante genérico (RICCI; SHAPIRA; ROKACH, 2015).

Os algoritmos de recomendação geralmente são classificados de acordo com a técnica utilizada para criar a recomendação, a saber: baseados em Conteúdo; Filtragem Colaborativa; Dados Demográficos; baseados em Conhecimento; baseados em Comunidades/Redes Sociais; Híbridos, combinação das técnicas anteriores (RICCI; SHAPIRA; ROKACH, 2015); baseados em entendimento de Contexto; baseados em reconhecimento de Risco; e, mais recentemente, baseados em Machine Learning (PORTUGAL; ALENCAR; COWAN, 2018).

O algoritmo baseado em Conteúdo aprende a recomendar itens semelhantes aos que o indivíduo gostou no passado por meio de classificação. A relação dos itens é preparada com base nas particularidades associadas aos itens comparados. Por exemplo, se um usuário classificou com cinco estrelas um livro que pertence ao gênero Biografia, o sistema aprende a recomendar outros livros desse gênero. Assim, na próxima vez em que o usuário acessar esse site de compra, haverá a recomendação de outras biografias. Adicionalmente, se o mesmo usuário também consultou livros sobre economia, haverá recomendações de livros de economia em complemento às indicações de biografias (NARA, 2019). As técnicas mais simples são baseadas em relações de palavras-chaves dos atributos dos produtos buscados com as palavras chaves do perfil do indivíduo (RICCI; SHAPIRA; ROKACH, 2015). Outro exemplo: um usuário está procurando um novo celular em uma loja online. Quando ele navega em um celular específico, o algoritmo reúne informações sobre esse produto e pesquisa em um banco de dados quais são os celulares com atributos semelhantes, como 
preço, velocidade de processamento e capacidade de memória. O resultado dessa pesquisa é retornado ao usuário como recomendação (PORTUGAL; ALENCAR; COWAN, 2018).

O algoritmo de recomendação desenvolvido com a técnica de Filtragem Colaborativa é o modelo que originou os primeiros sistemas de recomendação e apresenta recomendações com base em itens de que outros usuários com preferências semelhantes gostaram no passado (RICCI; SHAPIRA; ROKACH, 2015). Esta abordagem colaborativa considera os dados do usuário ao processar informações para recomendação. Por exemplo, ao acessar perfis de usuários em uma loja de games online, o algoritmo tem acesso a todos os seus dados, como idade, país, cidade e games comprados. Com essas informações, o sistema pode identificar outros usuários que compartilham da mesma preferência de games e sugere itens comprados por pessoas com preferências similares (PORTUGAL; ALENCAR; COWAN, 2018). A técnica de Filtragem Colaborativa se assemelha à técnica baseada em Conteúdo, mas com a característica de descobrir novos conteúdos ou itens que outras pessoas com perfil semelhante compraram anteriormente (NARA, 2019).

A similaridade da preferência de dois usuários é calculada com base na similaridade no histórico de classificação dos usuários (RICCI; SHAPIRA; ROKACH, 2015). A Filtragem Colaborativa é considerada a técnica mais popular e amplamente utilizada nos sistemas de recomendações. Em geral, o sistema baseado em Filtragem Colaborativa usa uma técnica de filtragem de informações com base na avaliação anterior de itens ou no histórico de compras anteriores do indivíduo (PARK et al., 2012). A Filtragem Colaborativa utiliza o método baseado na vizinhança, em outras palavras, o algoritmo se concentra nos relacionamentos "próximos" entre itens ou, alternativamente, entre usuários. É realizada uma abordagem item a item que modela a preferência de um usuário a um item com base nas classificações de itens semelhantes pelo mesmo usuário (NING; DESROSIERS; KARYPIS, 2015).

O algoritmo de Filtragem Colaborativa coleta as informações sobre o usuário para desenvolver recomendações e esta atividade pode ser realizada de forma explícita ou implícita. A coleta explícita de dados do usuário acontece quando os usuários estão cientes de que estão fornecendo suas informações. Por exemplo, ao se registrar em um site de notícias, os usuários geralmente preenchem um formulário que pergunta seu nome, idade e correio eletrônico. Outras formas de coleta explícita de dados do indivíduo ocorrem quando os usuários expressam suas preferências classificando itens usando um valor numérico ou uma preferência como "curtir" do Facebook. A coleta implícita de dados do usuário acessa informações sobre o usuário indiretamente. Por exemplo, ao visitar uma loja online, o servidor da loja online troca informações com o computador do usuário e, com base nisso, o 
algoritmo de recomendação da loja pode conhecer o navegador que o usuário usa e o país onde está localizado o usuário. Adicionalmente, algoritmos mais avançados monitoram os cliques do usuário e os registros de pressionamento de tecla (PORTUGAL; ALENCAR; COWAN, 2018).

O algoritmo de recomendação por Dados Demográficos se baseia no perfil demográfico do indivíduo para a recomendação do produto ou serviço. Esta técnica parte do princípio de que recomendações diferentes sejam geradas para diferentes grupos demográficos. Por exemplo os indivíduos são direcionados para sites específicos com base em seu idioma ou país (RICCI; SHAPIRA; ROKACH, 2015).

Os algoritmos de recomendação por Conhecimento são criados para situações específicas em contextos de produtos ou serviços mais complexos como carros, computadores, imóveis ou serviços financeiros uma vez que as técnicas de Filtragem Colaborativa com recomendações baseadas no histórico de compras do passado não seriam a melhor abordagem para a compra de um imóvel, pois o usuário não adquire imóveis com a mesma frequência com que compra livros. A técnica baseada em Conteúdo, na qual a recomendação é dada com base no item de que o indivíduo gostou no passado também não poderia ser aplicada para uma recomendação de serviços financeiros pois a aplicação que apresentou boa performance no passado não necessariamente oferecerá os mesmos ganhos no futuro.

Assim, os algoritmos de recomendação por Conhecimento são específicos para a necessidade de cada usuário e existem duas variações: a recomendação pode ser baseada em casos similares ou em requisitos específicos, avaliando-se necessidades específicas do indivíduo (FELFERNIG et al., 2015).

O algoritmo de recomendação baseado em Comunidade ou Redes Sociais, como o próprio nome diz, recomenda produtos com base nas preferências dos amigos do indivíduo. A crescente influência das redes sociais na vida cotidiana despertou o interesse no desenvolvimento de um sistema que adquire informações sobre as relações sociais dos indivíduos e as preferências de seus amigos. A recomendação é baseada nas classificações fornecidas pelos amigos do indivíduo e permitem uma aquisição abrangente de dados relacionados às relações sociais das pessoas (RICCI; SHAPIRA; ROKACH, 2015).

O algoritmo de recomendação híbrido é uma combinação das técnicas anteriores pois todas possuem pontos positivos e pontos negativos (BURKE, 2007). Por exemplo, sistemas de recomendações baseados em conteúdo carecem de um histórico de compras no caso do indivíduo ser um novo usuário que acessou o sistema de recomendação pela primeira vez. 
Nesse caso, o sistema híbrido pode compensar a falta do histórico com um sistema de recomendação social que busca informações sobre os amigos do indivíduo para recomendar um primeiro produto. O sistema híbrido não se limita somente a este exemplo pois podem ser feitas outras combinações das técnicas anteriores de acordo com o propósito de oferecer a melhor recomendação para o consumidor (RICCI; SHAPIRA; ROKACH, 2015).

O algoritmo baseado em Contexto leva em conta um conjunto de informações sobre o estado atual do usuário, como a hora do local onde se encontra o indivíduo (manhã, tarde, noite) ou sua atividade (inativa, em execução, em suspensão). A quantidade de informações de contexto a serem processadas é alta, tornando as recomendações baseadas em Contexto um campo de pesquisa desafiador (PORTUGAL; ALENCAR; COWAN, 2018).

Os algoritmos de reconhecimento de Risco, por sua vez, são uma variação dos algoritmos baseados em Contexto e levam em consideração um contexto no qual informações críticas estão disponíveis, como por exemplo os sinais vitais do indivíduo. É ciente dos riscos, porque uma decisão errada pode ameaçar a vida de um usuário ou causar danos. Exemplos de aplicações poderiam ser a recomendação de medicamentos e indicações de compra ou venda de ações (PORTUGAL; ALENCAR; COWAN, 2018).

Por fim, há muitos algoritmos de Machine Learning (ML) propostos na literatura, que podem ser classificados com base na abordagem usada no seu processo de aprendizagem (PORTUGAL; ALENCAR; COWAN, 2018). Existem quatro classificações principais: supervisionado, sem supervisão, parcialmente supervisionado e de reforço.

O algoritmo de ML com aprendizado supervisionado possui uma informação que serve como referência para o aprendizado de novas informações do mundo real, como um "treinamento". Por exemplo, na classificação de livros na livraria, existe uma informação prévia de que os livros devem ser organizados por gênero, autor e número de páginas. $\mathrm{O}$ algoritmo aprende essa classificação e quando a livraria recebe um novo livro, este é classificado de acordo com o "treinamento" recebido pelo algoritmo (PORTUGAL; ALENCAR; COWAN, 2018).

O algoritmo de ML sem supervisão de aprendizado precisa aprender com os dados do mundo real sem uma informação prévia. É geralmente utilizado para encontrar padrões ocultos nos dados. Por exemplo, o algoritmo pode ter acesso à rede social do usuário e classificá-lo em perfis psicológicos como extrovertidos ou reservados e, assim, a companhia detentora da rede social pode apresentar campanhas de marketing específicas (PORTUGAL; ALENCAR; COWAN, 2018). 
Os algoritmos de ML parcialmente supervisionados trabalham com um "treinamento" prévio, mas devem aprender com a falta de informações do mundo real (PORTUGAL; ALENCAR; COWAN, 2018). Por exemplo, o algoritmo deve classificar filmes com base no rating dos usuários. No mundo real existem usuários que não fazem a classificação e mesmo assim o algoritmo deve ser capaz de analisar, inferir conclusões e realizar a classificação (PORTUGAL; ALENCAR; COWAN, 2018).

Afinal, o algoritmo de ML com abordagem de aprendizado por reforço é o modelo em que o algoritmo recebe feedback externo de uma inteligência ou do ambiente externo. Por exemplo, em uma situação de jogo eletrônico, quando o algoritmo faz um movimento e tem um resultado positivo, ele deve repetir a ação. Caso contrário, se o feedback for negativo, ele deve evitar a ação (PORTUGAL; ALENCAR; COWAN, 2018).

A apresentação dos conceitos acima foi importante para proporcionar uma compreensão do contexto geral em que se encontram os algoritmos de recomendação e a partir desse ponto concentrar a pesquisa no aspecto comportamental do consumidor, aprofundando os estudos na atuação do Processo de Elicitação de Preferências frente as recomendações expressadas por um agente algorítmico.

\subsection{ARTIGOS RECENTES SOBRE ACEITAÇÃO DE ALGORITMOS E O PROCESSO DE ELICITAÇÃO DE PREFERÊNCIAS}

As pesquisas sobre algoritmos de recomendação se iniciaram na metade da década de 90 com estudos sobre a Filtragem Colaborativa (PORTUGAL; ALENCAR; COWAN, 2018; RICCI; SHAPIRA; ROKACH, 2015) e, desde então, os trabalhos seguem evoluindo em novas aplicações (HEGNER; BELDAD; BRUNSWICK, 2019) e despertando interesses em outras áreas de conhecimento.

Verruck e Nique (2017) realizaram um levantamento das pesquisas feitas nos últimos 20 anos utilizando os métodos bibliométrico e cientométrico e identificaram que existem duas linhas de pesquisas mais utilizadas pelos estudiosos. A primeira está relacionada a aspectos técnicos e computacionais de como melhorar a acurácia e eficiência do algoritmo. A segunda, por sua vez, busca entender como o comportamento do usuário é influenciado pela interação com o algoritmo de recomendação (VERRUCK; NIQUE, 2017), enfoque desta pesquisa exploratória.

Os pesquisadores constataram que, de um total de 979 artigos publicados usando palavras-chaves como "sistemas de recomendação" ou "agentes de recomendação", 175 
artigos estavam fora do domínio computacional. Em outras palavras, somente $18 \%$ dos artigos publicados pesquisaram aspectos sobre o comportamento do consumidor com os algoritmos de recomendação.

Verruk e Nique (2017) encontraram 175 artigos que poderiam ser classificados como pesquisas sobre os aspectos comportamentais do uso de algoritmos de recomendação, porém os mais influentes artigos em número de citações foram revisões com proposições teóricas. Os pesquisadores observaram que o número de publicações sobre questões computacionais vem diminuindo constantemente, mas, surpreendentemente, a quantidade de publicações na linha de pesquisa comportamental em relação ao algoritmo de recomendação não diminuiu na mesma proporção ao longo dos anos, o que sinaliza que ela ainda permanece como uma linha interessante de pesquisa. Os pesquisadores sugerem que futuras pesquisas se concentrem em replicação dos trabalhos anteriores e realização de novos experimentos para a confirmação dos modelos teóricos já existentes para, assim, fazer o conhecimento sobre o comportamento do usuário com os algoritmos de recomendação evoluir.

Poucos estudos empíricos foram encontrados por Verruk e Nique (2017), assim se tornou relevante a construção de uma revisão da literatura com artigos que desenvolveram experimentos relacionados a temática desta pesquisa. As bases de dados utilizadas na revisão de literatura foram "Web of Science" e "Google Scholar" e a busca foi por artigos publicados nos últimos 15 anos que continham investigações empíricas na aceitação das recomendações algorítmicas ou pesquisas relacionadas com os processos de elicitação de preferências sob a ótica comportamental. Abaixo um quadro resumo dos principais artigos que nortearam este trabalho de pesquisa. 
Quadro 1 - Principais artigos que nortearam o presente trabalho

\begin{tabular}{|c|c|c|}
\hline Artigo & Principal Alegação do Artigo & Variáveis \\
\hline $\begin{array}{l}\text { Gretzel e } \\
\text { Fesenmaier } \\
(2005)\end{array}$ & $\begin{array}{l}\text { - O Processo de Elicitação de } \\
\text { Preferências (PEP) cria uma } \\
\text { expectativa de qualidade na } \\
\text { recomendação do algoritmo que } \\
\text { influencia sua aceitação. } \\
\text { - O PEP tem um impacto } \\
\text { significativo na avaliação do } \\
\text { algoritmo e pode gerar três } \\
\text { interpretações sobre a } \\
\text { recomendação: Esforço, } \\
\text { relevância e transparência da } \\
\text { forma como é conduzida a } \\
\text { elicitação. }\end{array}$ & $\begin{array}{l}\text { Independentes: } \\
\text { - Esforço do usuário em responder } \\
\text { os questionamentos sobre suas } \\
\text { preferências; } \\
\text { - Relevância percebida das } \\
\text { perguntas de elicitação com o tema } \\
\text { da recomendação; } \\
\text { - Transparência da forma da } \\
\text { elicitação, se explícita ou } \\
\text { implícita. } \\
\text { Dependentes: } \\
\text { - Personalização percebida do PEP; } \\
\text { - Satisfação percebida com a } \\
\text { interação com o PEP; } \\
\text { - Acerto percebido da } \\
\text { recomendação com as preferências } \\
\text { providas pelo respondente }\end{array}$ \\
\hline $\begin{array}{l}\text { Knijnenburg, } \\
\text { Reijmer e } \\
\text { Willemsen } \\
(2011)\end{array}$ & $\begin{array}{l}\text { - A satisfação com o Processo de } \\
\text { Elicitação de Preferências para } \\
\text { cada indivíduo depende das } \\
\text { características individuais na } \\
\text { tomada de decisão e escolha. }\end{array}$ & $\begin{array}{l}\text { - Independentes: } \\
\text { - Conhecimento do domínio; } \\
\text { - Propensão a confiança; } \\
\text { Persistência. } \\
\text { - Dependentes: } \\
\text { - Controle percebido; } \\
\text { - Compreensão do Processo de } \\
\text { Elicitação de Preferências; } \\
\text { - Satisfação com a interface de } \\
\text { usuário; } \\
\text { - Efetividade percebida do sistema, } \\
\text { - Satisfação com a escolha; } \\
\text { - Confiança no sistema. }\end{array}$ \\
\hline $\begin{array}{l}\text { Dietvorst, } \\
\text { Simmons } \\
\text { Massey } \\
\text { (2015a) }\end{array}$ & $\begin{array}{l}\text { - Preferência geral por } \\
\text { recomendação de pessoas em } \\
\text { oposição ao algoritmo. } \\
\text { - Se o algoritmo apresenta um erro } \\
\text { na previsão, os indivíduos } \\
\text { demonstram certa intolerância ao } \\
\text { erro, perdem a confiança no } \\
\text { algoritmo e deixam de utilizá-lo. } \\
\text { - Comparando-se o algoritmo e uma } \\
\text { pessoa, a diminuição da confiança } \\
\text { é mais rápida com o algoritmo. }\end{array}$ & $\begin{array}{l}\text { - Independentes: } \\
\text { - Desempenho anterior nas } \\
\text { previsões (algoritmo ou pessoa). } \\
\text { - Dependente: } \\
\text { - Nova Previsão; } \\
\text { - } \\
\text { - Mediador: } \\
\text { - Confiança mediou a adoção do } \\
\text { algoritmo em uma nova previsão, } \\
\text { mas não aconteceu o mesmo para } \\
\text { o caso de se usar pessoa. } \\
\text { - }\end{array}$ \\
\hline
\end{tabular}

Continua... 
...Continuação

\begin{tabular}{|c|c|c|}
\hline $\begin{array}{l}\text { Dietvorst, } \\
\text { Simmons } \\
\text { Massey } \\
(2015 b)\end{array}$ & $\begin{array}{l}\text { - Preferência por algoritmo quando } \\
\text { existe intervenção no desempenho } \\
\text { do algoritmo para minimizar o } \\
\text { erro. }\end{array}$ & $\begin{array}{l}\text { - Independente: } \\
\text { - Intervenção no desempenho do } \\
\text { algoritmo. } \\
\text { - Dependente: } \\
\text { - Escolha entre aceitar a } \\
\text { recomendação do algoritmo ou a } \\
\text { própria recomendação. }\end{array}$ \\
\hline $\operatorname{Logg}(2017)$ & $\begin{array}{l}\text { - Preferência por algoritmo em } \\
\text { decisões objetivas (decisão com } \\
\text { base na razão) e preferência por } \\
\text { pessoa em decisões subjetivas } \\
\text { (decisão com base na emoção). }\end{array}$ & $\begin{array}{l}\text { - Independente: } \\
\text { - Origem da recomendação } \\
\text { (algoritmo ou pessoa). } \\
\text { - Dependente: } \\
\text { - Aceitação da recomendação } \\
\text { (quanto o respondente muda a sua } \\
\text { opinião inicial após receber a } \\
\text { recomendação). } \\
\text { - Moderador: } \\
\text { - Excesso de confiança; } \\
\text { - Conhecimento no domínio da } \\
\text { recomendação; } \\
\text { - Presença de especialista; } \\
\text { - Subjetividade da decisão. } \\
\text { - Mediador: } \\
\text { - Subjetividade da decisão. }\end{array}$ \\
\hline $\begin{array}{l}\text { Verruk e Nique } \\
\text { (2017) }\end{array}$ & $\begin{array}{l}\text { - Pesquisa bibliométrica e } \\
\text { cientométrica da literatura sobre } \\
\text { algoritmos de recomendações. } \\
\text { - Lacuna identificada em estudos } \\
\text { experimentais sobre o } \\
\text { comportamento do consumidor } \\
\text { com algoritmos. } \\
\text { - Sugestões de novas pesquisas que } \\
\text { investiguem o Processo de } \\
\text { Elicitação de Preferências. }\end{array}$ & $\begin{array}{l}\text { - Independentes mais encontradas } \\
\text { na revisão: } \\
\text { - Características do algoritmo de } \\
\text { recomendação; Confiança inicial } \\
\text { do usuário; Atitude com os } \\
\text { produtos recomendados; } \\
\text { - Familiaridade do usuário com o } \\
\text { produto. } \\
\text { - Variáveis dependentes mais } \\
\text { encontradas na revisão: } \\
\text { - Esforço na decisão; Confiança; } \\
\text { - Intenção de uso do algoritmo; } \\
\text { - Satisfação do usuário. }\end{array}$ \\
\hline
\end{tabular}

Continua... 


\begin{tabular}{|c|c|c|}
\hline & & \\
\hline $\begin{array}{l}\text { Jugovac, } \\
\text { Jannach } \\
\text { Dortmund } \\
\text { (2017) }\end{array}$ & $\begin{array}{l}\text { - Pesquisa dos últimos } 10 \text { anos de } \\
\text { trabalhos com Processo de } \\
\text { Elicitação de Preferências } \\
\text { publicados em conferências, } \\
\text { bibliotecas digitais e Google } \\
\text { Scholar. } \\
\text { - O trabalho não realizou } \\
\text { experimentos e nem indicou } \\
\text { potenciais constructos de estudos } \\
\text { futuros. } \\
\text { - O trabalho se concentrou no } \\
\text { processo explícito de elicitação de } \\
\text { preferências com análises dos } \\
\text { principais desafios no campo da } \\
\text { pesquisa. }\end{array}$ & $\begin{array}{l}\text { - Principais desafios: } \\
\text { - Eliminação de vieses de } \\
\text { preferências; } \\
\text { - Uso de Machine Learning; } \\
\text { - Maior engajamento do usuário ao } \\
\text { fornecer suas preferências. }\end{array}$ \\
\hline $\begin{array}{l}\text { Alexander, } \\
\text { Blinder e Zak } \\
(2018)\end{array}$ & $\begin{array}{l}\text { - A informação sobre a adoção do } \\
\text { algoritmo por outras pessoas foi } \\
\text { principal fator que gerou } \\
\text { confiança nos respondentes e } \\
\text { aumentou sua utilização. } \\
\text { - Indivíduos com tendência de } \\
\text { confiar em outras pessoas são } \\
\text { mais propensos à influência social } \\
\text { e, portanto, mais suscetíveis a } \\
\text { adotar o algoritmo. }\end{array}$ & $\begin{array}{l}\text { - Independentes: } \\
\text { - Prova social (informações sobre } \\
\text { nível de acerto dos algoritmos) } \\
\text { - Dependentes: } \\
\text { - Na situação em que o respondente } \\
\text { escolhia a ajuda do algoritmo } \\
\text { (confiança), foram coletadas } \\
\text { medições neurofisiológicas que } \\
\text { representavam a carga cognitiva e } \\
\text { o esforço para executar uma } \\
\text { tarefa. }\end{array}$ \\
\hline $\begin{array}{l}\text { Kramer, Borg, } \\
\text { Conitzer, } \\
\text { Sinnott- } \\
\text { Armstrong } \\
(2018)\end{array}$ & $\begin{array}{l}\text { - Em cenários de decisões difíceis } \\
\text { ou decisões com consequências } \\
\text { importantes (por exemplo, a troca } \\
\text { de doadores entre pessoas na fila } \\
\text { de espera para o transplante de } \\
\text { rim), as pessoas preferiram a } \\
\text { Inteligência Artificial (IA), } \\
\text { quando souberam que a IA já } \\
\text { havia tomado decisões } \\
\text { semelhantes. } \\
\text { - Constatou-se que a mudança de } \\
\text { preferência (de pessoa para } \\
\text { computador) pode ser } \\
\text { influenciada com a informação de } \\
\text { experiência passada da IA com o } \\
\text { tema da decisão. }\end{array}$ & $\begin{array}{l}\text { - Independentes: } \\
\text { - Informação que a Inteligência } \\
\text { Artificial tomou decisões de troca } \\
\text { de doadores de rim. } \\
\text { - Dependentes: } \\
\text { - Mudança de preferência pelo } \\
\text { decisor (pessoa ou IA), antes da } \\
\text { informação que a IA tomou } \\
\text { decisões semelhantes e depois que } \\
\text { o respondente recebeu a } \\
\text { informação. }\end{array}$ \\
\hline
\end{tabular}


...Continuação

\begin{tabular}{|c|c|c|}
\hline $\begin{array}{l}\text { Castelo, Bos e } \\
\text { Lehmann } \\
(2019)\end{array}$ & $\begin{array}{l}\text { - Os indivíduos confiam menos nos } \\
\text { algoritmos em tarefas subjetivas } \\
\text { por considerarem os algoritmos } \\
\text { inaptos para decidir em domínios } \\
\text { subjetivos. } \\
\text { - Porém, a subjetividade da tarefa } \\
\text { pode ser moderada. }\end{array}$ & $\begin{array}{l}\text { - Independente: } \\
\text { - Objetividade percebida da tarefa, } \\
\text { se objetiva (quantificável) versus } \\
\text { subjetiva (necessidade de } \\
\text { interpretação). } \\
\text { - Dependente: } \\
\text { - Confiança no algoritmo. } \\
\text { - Mediadores: } \\
\text { - Desconforto em usar o algoritmo; } \\
\text { - Eficácia do algoritmo. } \\
\text { - Moderador: } \\
\text { - Semelhança percebida do } \\
\text { algoritmo com pessoa. }\end{array}$ \\
\hline $\begin{array}{l}\text { Hegner, Beldad } \\
\text { e Brunswick } \\
(2019)\end{array}$ & $\begin{array}{l}\text { - Observaram que o aumento do } \\
\text { controle percebido eleva o nível } \\
\text { de confiança na tecnologia do } \\
\text { veículo autônomo e na aceitação } \\
\text { do algoritmo. } \\
\text { - Inovatividade pessoal foi uma } \\
\text { característica encontrada que } \\
\text { influencia na Intenção de Adoção. }\end{array}$ & $\begin{array}{l}\text { - Independente: } \\
\text { - Confiança/Controle; } \\
\text { - Utilidade percebida; } \\
\text { - Facilidade de uso } \\
\text { - Dependente: } \\
\text { - Intenção de Adoção } \\
\text { - Mediador: } \\
\text { - Utilidade Percebida } \\
\text { - Moderador: } \\
\text { - Inovatividade }\end{array}$ \\
\hline $\begin{array}{l}\text { Logg, Minson } \\
\text { e Moore (2019) }\end{array}$ & $\begin{array}{l}\text { - Preferência geral por algoritmo } \\
\text { em oposição a pessoa. } \\
\text { - Novatos tendem a confiar mais no } \\
\text { algoritmo e experientes tendem a } \\
\text { confiar mais no próprio } \\
\text { julgamento. }\end{array}$ & $\begin{array}{l}\text { - Independente: } \\
\text { - Origem da recomendação } \\
\text { (algoritmo ou pessoa). } \\
\text { - Dependente: } \\
\text { - Alteração na decisão, quanto o } \\
\text { indivíduo ajusta sua decisão } \\
\text { original após a recomendação. }\end{array}$ \\
\hline
\end{tabular}

Continua... 
Conclusão

\begin{tabular}{|c|c|c|}
\hline $\begin{array}{l}\text { Yeomans et al } \\
\text { (2019) }\end{array}$ & $\begin{array}{l}\text { - Os indivíduos precisam entender } \\
\text { como o algoritmo cria a } \\
\text { recomendação para que ela seja } \\
\text { aceita; } \\
\text { - A precisão do algoritmo não é um } \\
\text { fator suficiente para sua aceitação. } \\
\text { Os indivíduos normalmente } \\
\text { desconhecem a formação da } \\
\text { recomendação. }\end{array}$ & $\begin{array}{l}\text { - Independentes: } \\
\text { - Fonte/Origem da recomendação } \\
\text { (algoritmo ou pessoa). } \\
\text { - Dependentes: } \\
\text { - } \\
\text { - Qualidade da fonte de } \\
\text { recomendação. } \\
\text { - Mediador: } \\
\text { - Compreensão subjetiva do } \\
\text { processo de recomendação. } \\
\text { - Nota: } \\
\text { - Neste caso, o conhecimento } \\
\text { subjetivo era sobre a outra pessoa, } \\
\text { o par, ou seja, o respondente } \\
\text { achava que conhecia melhor o } \\
\text { companheiro e, portanto, } \\
\text { entenderia melhor as preferências } \\
\text { do companheiro. Assim, ele } \\
\text { possuía um conhecimento } \\
\text { subjetivo maior. }\end{array}$ \\
\hline $\begin{array}{l}\text { Germann e } \\
\text { Merkle (2020) }\end{array}$ & $\begin{array}{l}\text { - Preferência por algoritmo em } \\
\text { oposição a pessoa (domínio } \\
\text { financeiro). } \\
\text { - Não foram detectados aversão ao } \\
\text { algoritmo nem a perda de } \\
\text { confiança em situações com erros. }\end{array}$ & $\begin{array}{l}\text { - Independente: } \\
\text { - Experiência com o desempenho } \\
\text { (algoritmo ou pessoa) em } \\
\text { investimentos. } \\
\text { - Dependente: } \\
\text { - Seleção do gestor do investimento } \\
\text { (algoritmo ou pessoa) }\end{array}$ \\
\hline $\begin{array}{l}\text { Longoni e Cian } \\
\text { (2020) }\end{array}$ & $\begin{array}{l}\text { - Contexto utilitário ou hedônico no } \\
\text { processo decisório. } \\
\text { - A escolha pela recomendação de } \\
\text { um algoritmo é influenciada pela } \\
\text { característica utilitária da decisão. } \\
\text { - Por outro lado, se a situação } \\
\text { apresenta uma importância nos } \\
\text { aspectos hedônicos, a escolha é } \\
\text { pela recomendação de pessoas. }\end{array}$ & $\begin{array}{l}\text { - Independente: } \\
\text { - Característica utilitária ou } \\
\text { hedônica na decisão. } \\
\text { - Dependente: } \\
\text { - Recomendação de algoritmo ou de } \\
\text { pessoa. } \\
\text { - Mediador: } \\
\text { - Percepção da competência do } \\
\text { algoritmo. }\end{array}$ \\
\hline
\end{tabular}

Fonte: Autor

A tabela acima representa um resumo dos artigos que desenvolveram experimentos investigando o comportamento do consumidor com algoritmos de recomendação e apresentam explicações complementares sobre a aceitação Veruk e Nique (2017). A revisão da literatura foi importante para levantar as principais linhas de pensamentos encontradas como por exemplo. a precisão do algoritmo, o tipo de tarefa, o desconhecimento da lógica interna do algoritmo e o processo de elicitação de preferências. Elas serão discutidas em detalhes nas próximas sessões e a primeira linha de pensamento diz respeito a precisão do 
algoritmo com a recomendação, ou seja, quanto mais preciso for o algoritmo, maior a sua aceitação e vice-versa.

\subsubsection{Influência da precisão na adoção do algoritmo}

Como indicado por Veruk e Nique (2017) em seu levantamento bibliométrico e cientométrico sobre algoritmos de recomendação, $82 \%$ dos artigos publicados estudaram a performance computacional do algoritmo para encontrar a melhor recomendação. Então seria interessante iniciar o estudo analisando se de fato o desempenho computacional do algoritmo pode influenciar a aceitação da recomendação.

Dietvorst, Simmons e com Massey (2015) realizaram uma pesquisa indicando que os consumidores demonstraram perda de confiança nos algoritmos quando estes apresentavam desvios na recomendação. Em uma comparação de erros de previsão apresentados por algoritmos versus erros demonstrados por pessoas, os pesquisadores indicaram que os respondentes da pesquisa expressavam uma avaliação mais negativa do algoritmo na comparação com pessoas.

No estudo, os pesquisadores realizaram cinco experimentos em que os respondentes deveriam realizar prognósticos de duas situações: prever antecipadamente o desempenho dos alunos recém admitidos no curso de MBA e classificar todos os estados americanos em ordem decrescente pela quantidade de passageiros que viajaram de avião. Quanto maior o acerto das previsões, maior a premiação em dinheiro para os participantes, que poderiam escolher a ajuda de um algoritmo ou de outra pessoa. Foi observado que mesmo quando o algoritmo apresentava um pequeno erro, os respondentes perdiam a confiança no algoritmo e deixavam de utilizá-lo. Por outro lado, os participantes não perdiam a confiança nas pessoas especialistas, mesmo quando elas apresentaram um erro maior que o algoritmo.

Os pesquisadores reconhecem que pouco se sabe sobre os motivos que levam os indivíduos a desenvolverem aversão a algoritmos e que ainda faltam pesquisas empíricas que comprovem tal situação (DIETVORST; SIMMONS; MASSEY, 2015).

Contrariamente às conclusões a pesquisa anterior, Germann e Merkle (2020) descobriram que os indivíduos aceitaram recomendações de algoritmos mesmo quando apresentaram erros. Os autores manipularam recomendações de investimentos financeiros em que a mesma recomendação foi apresentada por algoritmos ou por gestores financeiros. Os participantes da pesquisa não perderam a confiança no algoritmo de investimento quando este 
apresentou erros, contrariamente à situação identificada por Dietvorst, Simmons e Massey (2015a).

Germann e Merkle (2020) constataram que os respondentes aceitaram mais o algoritmo quando os indivíduos perceberam que os resultados apresentados pelos algoritmos eram mais eficientes que os apresentados pelos gestores humanos de aplicação. Ou seja, o resultado dado pelo algoritmo após a sua utilização não apenas atendeu às expectativas dos indivíduos como também alterou sua atitude inicial, levando as pessoas a adotá-lo. Germann e Merkle (2020) sugerem que uma vez atendidas as expectativas do indivíduo após o uso da recomendação, esta situação poderia ser um fator influenciador que mudaria a atitude do indivíduo em direção à adoção do algoritmo.

Yeomans et al (2019), por sua vez, realizaram uma pesquisa em que foram comparadas as recomendações de piadas dadas por algoritmos e recomendações apresentadas por seres humanos. Os pesquisadores desenvolveram um algoritmo de recomendação de filtragem colaborativa e suas recomendações eram estatisticamente mais precisas que as recomendações de pessoas uma vez que o algoritmo desenvolvido era uma equação de regressão obtida pela otimização dos dados coletados por meio da técnica dos mínimos quadrados.

Apesar da maior precisão do algoritmo ao recomendar uma piada de acordo com o gosto do usuário, os respondentes apresentaram uma tendência maior por sugestões oferecidas pelas pessoas ou pelo próprio julgamento. Essa descoberta demonstra que a resistência ao algoritmo permanece, não importando se o ele é mais preciso e livre de erros.

A seguir, será apresentada uma segunda linha de pensamento relacionada com a aceitação de recomendações de algoritmos em que pesquisadores analisaram as características objetiva/subjetiva ou utilitária/hedônica da tarefa.

\subsubsection{Influência do tipo de tarefa na adoção do algoritmo}

As conclusões sobre a precisão do algoritmo apresentada no item anterior não foram totalmente conclusivas e por esse motivo é relevante o conhecimento de uma segunda linha de pensamento encontrada na revisão da literatura. Um grupo de pesquisadores analisou como a percepção das características objetivas/subjetivas ou utilitária/hedônica da tarefa influenciaria a aceitação da recomendação. 
Castelo, Bos e Lehmann (2019) analisaram a aceitação do algoritmo sob a ótica da tarefa fim (“task"). Se a atividade é considerada subjetiva e requer emoção para a decisão, os indivíduos preferem recomendações de humanos. Por outro lado, se a atividade fim é considerada objetiva, a preferência é por recomendações provenientes de um algoritmo, como é o caso de uma recomendação financeira. Os pesquisadores manipularam a subjetividade da tarefa de forma a que ela fosse percebida como mais quantificável e as pessoas aumentaram a confiança nas recomendações oferecidas pelos algoritmos (CASTELO; BOS; LEHMANN, 2019).

Logg, Minson e Moore (2019), por sua vez, testaram a diferença de julgamento entre as recomendações provenientes de um algoritmo versus as recomendações dadas por uma pessoa. Em seu experimento, os respondentes deveriam estimar o peso de um indivíduo baseando-se somente em uma foto; na sequência, o peso do indivíduo era informado. Para um grupo foi dito que o algoritmo processou as informações de todos os demais participantes da pesquisa e calculou o peso. Mas, para um segundo grupo, foi dito que a informação de peso era proveniente de um participante da mesma pesquisa. Na etapa seguinte foi dada a opção para o respondente dizer se mudaria sua opinião inicial com base na segunda informação de peso. Quando a segunda informação foi dada, os respondentes confiaram mais no algoritmo, ou seja, os resultados concluem que os indivíduos tendem a adotar as recomendações de algoritmos. Os indivíduos demonstraram essa preferência em situações que envolviam eventos geopolíticos, popularidade de músicas e atratividade romântica de casais (LOGG; MINSON; MOORE, 2019).

Logg (2017) apontou também que decisões dentro de domínios considerados subjetivos, em que as decisões exigem mais emoção ou intuição no processo decisório, poderiam levar a um sentimento de aversão ao algoritmo, como por exemplo compra de livros, aluguel de filmes, ou recomendação de pares românticos (aplicativos de namoro). Nestas situações, os indivíduos preferiram recomendações de pessoas.

Por outro lado, a autora sugere também que domínios objetivos, definidos como sendo aqueles em que é possível uma mensuração ou quantificação de atributos, como situações de decisões financeiras, há uma tendência das pessoas preferirem os algoritmos de recomendação.

Longoni e Cian (2020), no entanto, estudaram a aceitação da recomendação de um algoritmo sob a ótica utilitária ou hedônica da tarefa. Os pesquisadores analisaram como variável independente o aspecto utilitário ou hedônico e como variável dependente a escolha por uma recomendação de um algoritmo ou de uma pessoa. Essa escolha dependerá da 
percepção de competência da Inteligência Artificial. De fato, as pessoas percebem diferentes níveis de competência com respeito à avaliação de atributos hedônicos ou utilitários. Em seu experimento, os pesquisadores testaram a mediação da percepção da competência como fator influenciador na adoção da recomendação. $\mathrm{O}$ estudo demonstrou que as pessoas acreditam que os algoritmos baseados em IA são menos competentes quando avaliam atributos hedônicos. Ao contrário, as pessoas escolhem as recomendações de IA quando os atributos utilitários são mais importantes ou evidentes. Os autores inferem que, desde a infância, somos ensinados que os computadores possuem um raciocínio mais lógico sem considerar o aspecto humano e, portanto, essa associação pode explicar o motivo de escolhas por algoritmo quando as variáveis utilitárias são mais evidentes (LONGONI; CIAN, 2020).

As alegações de precisão do algoritmo bem como o tipo de tarefa apresentaram uma certa ambiguidade de conclusões e por esse motivo é importante o conhecimento de outra linha de pensamento encontrada na literatura.

A seguir, será abordado uma terceira linha de pensamento que aponta para a incompreensão da lógica interna do algoritmo. O algoritmo pode ser percebido como uma “caixa preta" e o usuário não compreende como se chegou na recomendação, influenciando negativamente a sua aceitação.

\subsubsection{Influência do desconhecimento da lógica interna do algoritmo}

Outros pesquisadores descobriram que, potencialmente, as pessoas demonstraram uma aversão à recomendação do algoritmo porque não entendem como a recomendação foi gerada pelo algoritmo, ou seja, usuários não compreendem a lógica utilizada para se criar a recomendação e não sabem quais dados foram utilizados (YEOMANS et al., 2019). A pesquisa realizada por Yeomans et al. (2019) indica que os respondentes compreendem facilmente o processo mental das pessoas para formar uma recomendação, mas não compreendem o processo lógico realizado pelo algoritmo para chegar na recomendação. Eles sugerem que, caso fosse possível uma experimentação maior do algoritmo, os usuários entenderiam o processo de recomendação e assim passariam a aceitá-la.

Nesse sentido, Dietvorst, Simmons e Massey (2015b) pesquisaram a reação do consumidor caso fosse possível eliminar ou atenuar a possibilidade de erros do algoritmo. Os pesquisadores realizaram três experimentos em que foi possível realizar um ajuste pequeno na previsão do algoritmo. Os resultados indicaram que haveria uma tendência maior de adoção dos algoritmos com erros quando existisse a possibilidade de ajustá-los para minimizar o erro. 
Outra constatação foi que os respondentes não se importaram se o nível de ajuste do algoritmo era pequeno ou grande. Como conclusão do artigo, os pesquisadores sinalizaram que os indivíduos podem apresentar uma tendência maior de adoção do algoritmo caso seja possível a realização de interações ou ajustes (DIETVORST; SIMMONS; MASSEY, 2015b). É possível inferir que a possibilidade de ajustes na performance permitiu o entendimento de como o algoritmo chegou na recomendação, aumentando sua adoção.

Então se houvesse uma forma do usuário entender como a recomendação foi formulada pelo algoritmo é plausível alegar que haveria uma possibilidade de aumentar sua aceitação. O próximo item abordará um processo de interação entre o usuário e o algoritmo que poderia minimizar a incompreensão da lógica interna do algoritmo e influenciar positivamente a aceitação da recomendação algorítmica, o Processo de Elicitação de Preferências.

\subsubsection{Influência do processo de elicitação de preferências na adoção do algoritmo}

O Processo de Elicitação de Preferências (PEP) pode ser definido como a etapa inicial de interação do algoritmo em que as preferências do usuário são coletadas para a definição da recomendação. Ele pode ser um processo explicito, caracterizado pela solicitação direta das preferências do usuário, ou implícito em que as preferências são obtidas indiretamente. Atualmente as quatro formas mais comuns de elicitação explicitas são: escalas de classificação (ratings); pesos relativos associados aos atributos do produto e comentários realizados pelos usuários (KNIJNENBURG; WILLEMSEN, 2015).

A obtenção das preferências com base em escalas de classificação pode ser simplesmente a indicação de positivo/negativo (símbolo do dedão para cima ou para baixo), classificação pela quantidade de estrelas (5 ou 10 estrelas) ou qualquer outra classificação mensurável. Outro método explicito de coletar as preferências dos indivíduos é solicitar opiniões e comentários sobre exemplos ou sugestões. Um ponto de atenção, contudo, é que esse procedimento pode exigir um esforço maior de colaboração do usuário na transmissão de suas preferências (KNIJNENBURG; WILLEMSEN, 2015).

Por sua vez, a forma implícita é caracterizada pelo mapeamento da navegação do usuário na página web ou qualquer outra forma indireta de obtenção das preferências ou necessidades do indivíduo (KNIJNENBURG; WILLEMSEN, 2015).

De todo modo, um algoritmo de recomendação necessita de um certo número de ratings dos produtos ou, pelo menos, de uma base de dados inicial de informações para poder 
sugerir uma recomendação assertiva. Em muitos casos, porém, os indivíduos ainda não classificaram os produtos ou então são novos usuários que não possuem um histórico na base de dados. Esta situação é chamada de "cold start problem" ou "começo frio" do algoritmo de recomendação (KNIJNENBURG; WILLEMSEN, 2015; NARA, 2019). No entanto, existem formas de minimizar essa dificuldade utilizando as informações demográficas do usuário no momento do seu cadastro inicial como, por exemplo, o algoritmo de recomendação evitar o oferecimento de fraldas para um usuário de 15 anos (NARA, 2019). Os algoritmos híbridos tendem a administrar melhor a situação de "cold start" por meio de combinações de técnicas anteriormente descritas ou eventualmente encorajar os usuários a classificar mais itens (KNIJNENBURG; WILLEMSEN, 2015).

A revisão de literatura encontrou pesquisadores que analisaram a influência do Processo de Elicitação de Preferências (PEP) na aceitação da recomendação (GRETZEL; FESENMAIER, 2005; KNIJNENBURG; REIJMER; WILLEMSEN, 2011). Gretzel e Fesenmaier (2005) sinalizam que o Processo de Elicitação de Preferências é uma fase importante de interação entre o usuário e o algoritmo porque cria uma expectativa da qualidade da recomendação algorítmica. Assim, a forma como o usuário informa suas preferências pode ter um impacto significativo na avaliação das recomendações fornecidas pelo algoritmo (GRETZEL; FESENMAIER, 2005). Segundo os pesquisadores, o PEP pode gerar três interpretações sobre a recomendação: Relevância, se a recomendação terá relevância para o usuário; Transparência, percepção de que as preferências do usuário serão usadas na recomendação; Esforço, dedicação necessária por parte do usuário em responder a elicitação.

A pesquisa de Gretzel e Fesenmaier (2005) foi desenhada a partir de uma manipulação de três constructos (Relevância, Transparência e Esforço) com dois níveis para cada fator (alto/baixo). Durante o experimento, os indivíduos eram apresentados a um destino de "Spring Break" (feriado de primavera) entre cincos opções distintas assinalado randomicamente para o respondente, mas igualmente percebidos como atrativos em pré-testes realizados anteriormente pelos pesquisadores (GRETZEL; FESENMAIER, 2005). É importante observar que nesta situação a característica da tarefa pode ser considerada como subjetiva ou hedônica, pois refere-se a uma viagem de lazer.

A partir desse experimento, Gretzel e Fesenmaier (2005) concluíram que o Processo de Elicitação de Preferências pode influenciar na aceitação da recomendação fornecida pelo algoritmo. Um ponto interessante foi a manipulação da Relevância por meio de perguntas: Relevância Baixa era o cenário em que as perguntas não estavam relacionadas com a viagem; 
Relevância Alta foi a situação em que os indivíduos respondiam perguntas direcionadas à viagem. Curiosamente, Gretzel e Fesenmaier (2005) observaram que os indivíduos interpretaram as perguntas de relevância baixa, que não tinham relação com o destino de "Spring Break" como questões diretamente relacionadas com a viagem (GRETZEL; FESENMAIER, 2005).

Ao mesmo tempo, os pesquisadores indicaram que a Transparência é um fator importante para a percepção de personalização da recomendação, que, por sua vez, influencia na percepção de qualidade da recomendação. Portanto, os indivíduos precisam sentir que suas informações são usadas nas recomendações dos algoritmos (GRETZEL; FESENMAIER, 2005) e esse sentimento poderia levar ao entendimento da lógica interna do algoritmo na determinação da recomendação. Com efeito, a fase inicial de interação entre o usuário e o algoritmo na identificação de suas preferências pode gerar uma alta expectativa com respeito à qualidade da recomendação além de ser uma experiência importante para o usuário (GRETZEL; FESENMAIER, 2005).

$\mathrm{Na}$ revisão da literatura para esta pesquisa poucos artigos foram encontrados sobre o Processo de Elicitação de Preferências influenciando a aceitação de recomendação de algoritmos. Verruk e Nique (2017) indicaram que a principal lacuna encontrada em seu levantamento bibliométrico está relacionada com a identificação de constructos centrais da aceitação das recomendações, sendo o Processo de Elicitação de Preferência (PEP) um dos fatores considerados pelos pesquisadores.

O próximo item abordará o conhecimento do usuário sobre o domínio da recomendação que em estudos anteriores influenciou a satisfação do usuário com o PEP e com a aceitação do algoritmo (JUGOVAC; JANNACH; DORTMUND, 2017; KNIJNENBURG; REIJMER; WILLEMSEN, 2011; LOGG, 2017) e por essa razão se torna relevante abordar este tema na pesquisa.

\subsubsection{Influência do conhecimento prévio sobre o domínio da recomendação}

É possível que o conhecimento prévio que o usuário tem sobre o domínio da recomendação influencie na adoção do algoritmo.

No estudo conduzido por Logg (2017), a pesquisadora identificou que a adoção do algoritmo é moderado pelo excesso de confiança (“overconfidence”), pela presença de um especialista ("expert advisor") e pelo próprio conhecimento que a pessoa tem sobre o tema/decisão ("expertise"). Ela apontou que a preferência por um algoritmo diminuiu quando 
o indivíduo possuía um excesso de confiança, em decisões de escolha entre um algoritmo e um especialista externo (mesmo sabendo que a recomendação do especialista era menos precisa) e quando o indivíduo já possuía um conhecimento prévio sobre o assunto.

Logg (2017) indica também que as pessoas não aceitaram a recomendação do algoritmo porque seriam capazes de tomar as decisões por si sós. Assim, constatou-se que as pessoas preferem o próprio julgamento e desconsideram os conselhos de pares devido à percepção de se considerarem especialistas no processo de decisão ou por terem um excesso de confiança naquele momento.

Logg, Minson e Moore (2019) supõem que as pessoas prefiram aconselhamento de especialistas humanos à de outros pares e que esta preferência seja mais forte do que qualquer apreciação de algoritmos. Trabalhos futuros poderão investigar se de alguma forma esta situação impactaria a aceitação da recomendação de algoritmos.

Em outra pesquisa, Knijnenburg, Reijmer e Willemsen (2011) compararam como diferentes Processos de Elicitação de Preferências podem interferir nos usuários que apresentam características diferentes em termos de conhecimento subjetivo sobre economia de energia. Os pesquisadores indicaram que pessoas com mais conhecimentos (especialistas) estão mais satisfeitas com processos de elicitação explícitos e híbridos e pessoas com menos conhecimento (novatos) preferem formatos sem interação. Em outras palavras, Knijnenburg, Reijmer e Willemsen (2011) concluem que a satisfação com a recomendação pode depender do nível de conhecimento do usuário.

Knijnenburg, Reijmer e Willemsen (2011) constataram que as pessoas com pouco conhecimento sobre economia de energia (novatos) preferem métodos de interação que não exijam um conhecimento muito profundo dos atributos, especialmente quando utilizam o Processo de Elicitação de Preferências em que a classificação dos atributos foi da maior popularidade para a menor porque se sentem com mais controle da situação. Já as pessoas com mais conhecimentos sobre economia de energia (especialistas) preferiram os modelos de PEP que lhes permitissem controlar o algoritmo e aproveitassem o seu conhecimento sobre os atributos de economia de energia.

Jugovac, Jannach e Dortmund (2017), mais recentemente, realizaram uma revisão sistemática de pesquisas sobre o Processo de Elicitação de Preferências dos últimos 10 anos com base em artigos publicados em bibliotecas digitais e no Google Scholar e dentre as melhorias ou novos desenvolvimentos sugeridos pelos pesquisadores, está a questão de adequar a forma de elicitação de preferências de acordo com o nível de conhecimento que o usuário possui sobre o tema da recomendação. De fato, a revisão da literatura identificou 
poucos experimentos em que o conhecimento subjetivo foi analisado, indicando que ele pode ser um tópico interessante a ser investigado.

A seguir, são destacados os principais traços individuais encontrados na revisão da literatura pois são igualmente importantes para identificar as recentes descobertas e explorar novas particularidades que podem afetar a satisfação com o Processo de Elicitação de Preferências.

\subsubsection{Traços individuais e o processo de elicitação de preferências}

Knijnenburg, Reijmer e Willemsen (2011) identificaram em seu experimento que usuários com menos propensão a confiar em outras pessoas se sentem poucos satisfeitos com os processos de elicitação Top N, Explícito e Classificação. Com respeito à persistência na tomada de decisão, os pesquisadores identificaram que os maximizadores estão mais contentes com as suas escolhas em comparação com os satisfeitos porque o algoritmo oferece informações detalhadas de oitenta recomendações, aumentando as chances dos maximizadores selecionarem as melhores recomendações. Por outro lado, a maior satisfação dos maximizadores só é significativa quando os atributos são classificados da maior para a menor popularidade porque este Processo de Elicitação de Preferências (PEP) poderia evitar compensações, ou, em outras palavras, evitar o pensamento contrafactual e o arrependimento antecipado após a tomada de decisão.

Uma característica identificada por Logg (2017) foi a facilidade com números, ou seja, a numeracia. A pesquisadora conclui que as pessoas adotam o algoritmo quando se sentem mais confortáveis com o raciocínio lógico e o processo de decisão é considerado mais racional.

Alexander, Blinder e Zak (2018) realizaram uma pesquisa neurofisiológica com foco na confiança como fator de adoção dos algoritmos. Um ponto importante identificado para a geração de confiança nos respondentes foi a informação de que outras pessoas já haviam adotado a inteligência artificial para essa utilização. Quando os participantes da pesquisa souberam que outras pessoas fizeram uso do algoritmo, adotaram-no com mais frequência. Os pesquisadores nomearam esse constructo de "prova social" e manipularam os grupos com alta e baixa prova social. Adicionalmente, indicaram que os indivíduos que demonstram confiança em pessoas são mais propensos à influência social e, portanto, mais suscetíveis a adotarem o algoritmo (ALEXANDER; BLINDER; ZAK, 2018). 
A pesquisa de Hegner, Beldad e Brunswick (2019) sobre adoção de veículos autônomos concentrara-se igualmente no constructo confiança e controle. Os autores indicaram que na medida em que o controle percebido pelo respondente aumenta, aumenta também a confiança na tecnologia do veículo autônomo, o que, por sua vez, reduz a incerteza sobre o resultado da transação, que é a condução do veículo por meio de uma inteligência artificial (HEGNER; BELDAD; BRUNSWICK, 2019). Constataram que, ao oferecer o controle para carros autônomos, ou seja, ao diminuir o controle para o respondente, a intenção de uso dos veículos autônomos é influenciada negativamente. Em outras palavras, um senso de controle maior reduz o risco percebido de falha da inteligência do veículo.

Hegner, Beldad e Brunswick (2019) sugerem medir percepções de controle específicas dentro da situação em que se encontra o respondente como fator-chave na geração de confiança. Os autores mencionam também a inovatividade do indivíduo como um traço de personalidade que aumenta a propensão à adoção de veículos autônomos e concluem que a confiança na tecnologia e a preocupação com a perda de controle são constructos fortemente inter-relacionados.

Outra recente pesquisa estudou se as pessoas eram mais propensas a aceitar a recomendação de seres humanos ou de algoritmos em decisões cujas consequências tinham um peso muito importante, como a troca de doadores para transplantes de rim (KRAMER et $a l ., 2018)$. Para um grupo, os pesquisadores informaram que algoritmos foram utilizados em situações semelhantes de decisão e para outro grupo essa informação foi omitida. Constatouse uma escolha maior por recomendações dadas pelo algoritmo no primeiro grupo quando os pesquisados receberam a informação do uso de algoritmos. Em outras palavras, os pesquisados tenderam a escolher o algoritmo quando já tinham ouvido falar sobre o uso de algoritmos em situações semelhantes.

Nesse experimento, Kramer et al. (2018) mediram dados demográficos, propensão ao uso de computadores e características individuais utilizando várias escalas psicométricas: Escala Social e Econômica de Conservadorismo, uma medida de preferência política; Escala de Identidade Moral, uma medida da importância de certos traços morais para a autoimagem; Escala de Propensão a Risco, uma medida de busca/aversão ao risco; Escala de Repugnância Revisada, uma medida de perfil de repulsa às características; Questionário de Fundamentos Morais, uma medida dos conceitos morais que um participante normalmente emprega e se preocupa; Questionário de Empatia Adaptada, uma medida dos traços de empatia; Escala de Psicopatia de Autorrelato, uma medida de traços psicopáticos; Inventário Arnett de Busca de 
Sensações, uma medida de predileção para procurar situações de alta excitação; Escala de Impulsividade Abreviada, uma medida da impulsividade das características individuais.

Surpreendentemente, os traços individuais e os dados demográficos medidos não tiveram influência significativa e somente a influência social foi o constructo que mais teve impacto sobre a probabilidade dos respondentes escolherem o uso de algoritmos em decisões com consequências importantes (KRAMER et al., 2018). Outrossim, Kramer e seus colegas sugerem que na medida em que os algoritmos continuem a ser utilizados em decisões cada vez mais importantes e suas implementações se tornem cada vez mais visíveis para a sociedade, a aceitação de recomendações de algoritmos se tornará mais natural para as pessoas.

O próximo item sumariza as lacunas encontradas na revisão da literatura e apresenta os objetivos desta pesquisa exploratória. 


\section{LACUNAS E OBJETIVOS}

Como observado nas sessões anteriores, as pesquisas empíricas encontradas na revisão da literatura apresentaram dados estimulantes e explicações interessantes sobre a aceitação de recomendações de algoritmo, mas ao mesmo tempo algumas lacunas foram observadas e novos caminhos de investigação são necessários.

Analisando-se a precisão do algoritmo, foram encontradas situações conflitantes na análise dos artigos. De um lado, recomendações de algoritmos foram aceitas quando os algoritmos eram precisos no experimento de Dietvorst, Simmons e Massey (2015a), mas de outro lado, situação oposta ocorreu no estudo de Germann e Merkle (2020) em que a precisão não foi necessariamente a questão fundamental. Já no experimento com piadas de Yeomans et al (2019), as pessoas preferiram recomendações de pares e os algoritmos, estatisticamente mais precisos, não eram aceitos.

Assim, é possível que existam outros fatores além da precisão que podem influenciar a aceitação do algoritmo. Logg, Minson e Moore (2019) sugerem examinar como as recomendações de algoritmos podem ser aceitas antes de qualquer informação sobre sua performance ou precisão.

Essa situação ambígua da precisão do algoritmo levou a análise da segunda linha de alegações encontrada na revisão da literatura em que pesquisadores indicam que o tipo de tarefa objetiva/subjetiva ou utilitária/hedônica seriam os principais fatores da aceitação da recomendação algorítmica.

Porém, da mesma forma, estes estudos sobre a percepção do usuário com relação a tarefa ser objetiva/subjetiva ou hedônica/utilitária não esclarecem totalmente a aceitação da recomendação de um algoritmo. Castelo, Bos e Lehmann (2019) observaram que, na medida em que exemplos reais de algoritmos com habilidades afetivas eram apresentados aos respondentes, eles aumentaram a confiança nos algoritmos com tarefas consideradas subjetivas. Logg, Minson e Moore (2019), por sua vez, notaram que os respondentes aceitaram algoritmos para recomendações de atratividade romântica de casais, um domínio considerado subjetivo. Portanto a alegação da influência das características objetivas/subjetivas ou utilitárias/hedônicas da tarefa também apresenta uma certa ambiguidade.

Sob outra perspectiva, é possível imaginar que o algoritmo é percebido como uma "caixa preta" e as pessoas não compreendem como o algoritmo cria a recomendação (YEOMANS et al., 2019). Dessa forma, a falta de compreensão da lógica interna do 
algoritmo pode desenvolver uma desconfiança e estimular a rejeição do algoritmo de recomendação. Portanto se existir uma forma de aumentar a consciência sobre a lógica interna do algoritmo, é possível supor que a recomendação de um algoritmo seja melhor aceita, independentemente da sua precisão ou tipo de tarefa na qual a recomendação estaria inserida.

Nesse sentido, Gretzel e Fesenmaier (2005) indicaram que a maneira como o usuário informa suas preferências, gostos e necessidades gera um sentimento de transparência na criação da recomendação e, portanto, pode-se criar a percepção de que tais informações serão usadas pelo algoritmo. Em outras palavras, é plausível supor que o sujeito entenderia o desenvolvimento da recomendação por meio do processo de elicitação de preferências (PEP) e desse modo minimizar o seu desconhecimento com a lógica interna do algoritmo.

Longoni e Cian (2020) afirmam que as pessoas precisam perceber a competência do algoritmo para que a recomendação seja aceita. De forma complementar, Gretzel e Fesenmaier (2005) apontam que o PEP cria uma percepção de relevância na recomendação, ou seja, a recomendação se faz importante e verdadeira para o usuário. Assim seria possível inferir que os indivíduos poderiam perceber a competência do algoritmo por meio do processo de elicitação de preferências.

Outra lacuna encontrada na revisão da literatura diz respeito ao conhecimento subjetivo que o indivíduo tem sobre o domínio da recomendação. Pesquisadores apontaram que o conhecimento subjetivo pode exercer influência no processo de elicitação de preferências (JUGOVAC; JANNACH; DORTMUND, 2017; KNIJNENBURG; REIJMER; WILLEMSEN, 2011; LOGG, 2017). Em qualquer situação de uso de algoritmos de recomendação, há usuários com diversos níveis de conhecimento sobre o campo da recomendação. Algumas pessoas são iniciantes no assunto e não conhecem nada sobre o tema e outros indivíduos especialistas que entendem muito bem do assunto com preferências e opiniões definidas. Assim, pode ser importante adaptar o PEP de acordo com o conhecimento do usuário e, dessa forma, melhorar sua experiência com o algoritmo de recomendação (KNIJNENBURG; WILLEMSEN, 2010).

Assim as lacunas encontradas levam as seguintes perguntas de pesquisa: É possível que diferentes PEPs podem influenciar a satisfação com a recomendação do algoritmo e que uma determinada forma de PEP pode gerar mais satisfação que a outra? Diferentes níveis de conhecimento subjetivo sobre o domínio da recomendação podem influenciar a satisfação com a recomendação, ou seja em que medida ter pouco conhecimento ou muito conhecimento sobre o tema da recomendação interfere na satisfação do usuário? O PEP pode influenciar a aceitação de recomendações de itens considerados hedônicos ou de natureza subjetiva? 
Com efeito, poucos experimentos foram encontrados na revisão de literatura analisando o Processo de Elicitação de Preferências (PEP) e tampouco pesquisas empíricas investigando o efeito entre variações do PEP de acordo com o nível de conhecimento do usuário ou estudos envolvendo o PEP com tarefas consideradas subjetivas ou hedônicas.

Gretzel e Fesenmaier (2005) indicam que o PEP é uma experiência importante para a satisfação com a recomendação do algoritmo e carece de novas pesquisas empíricas. Analogamente, Knijnenburg e Willemensen (2010) apontam a influência do PEP na aceitação da recomendação e sugerem a necessidade de novos estudos empíricos. Adicionalmente Verruk e Nique (2017) acreditam que novos experimentos poderiam ser realizados para avaliar o comportamento das pessoas com o PEP. E por fim, Jugovac, Jannach e Dortmund (2017) também observaram que o PEP é pouco estudado ou quando examinado, é negligenciado nos trabalhos de pesquisa.

Assim, o objetivo geral desta pesquisa exploratória é estudar a influência do processo de elicitação de preferências (PEP) na satisfação do indivíduo com a recomendação de um algoritmo. Complementarmente os objetivos específicos são analisar a satisfação com a recomendação de acordo com diferentes PEPs e níveis de conhecimento sobre domínio, verificar a intenção de compra de um item subjetivo/hedônico dentro deste contexto e identificar novos traços individuais que possam atuar na aceitação da recomendação.

A sessão seguinte abordará a metodologia de pesquisa utilizada, descrevendo o desenho planejado, os procedimentos implementados, as medidas e análise dos dados. Os participantes foram convidados a participar de um experimento que simulou um sistema de recomendações de cervejas especiais baseado em inteligência artificial. 


\section{METODOLOGIA DE PESQUISA}

A metodologia desta pesquisa consistiu em realizar um estudo quantitativo com a execução de um experimento, manipulando cinco diferentes maneiras de obter as informações sobre os gostos e interesses do usuário e sua reação com respeito à recomendação de cervejas especiais. O plano de fundo do experimento é a simulação de um algoritmo de recomendação de cervejas especiais brasileiras baseado em inteligência artificial com um processo de elicitação de preferência explícito, por se tratar do processo mais comum encontrada na literatura (JUGOVAC; JANNACH; DORTMUND, 2017).

\subsection{DESENHO DA PESQUISA}

O domínio de conhecimento escolhido para a realização deste experimento foi a cerveja pelo fato de ser uma bebida bastante popular no Brasil (LAPORTA, 2018). É provável que muitas pessoas tenham um conhecimento mínimo sobre cervejas e, em algum momento, já experimentaram o produto, mesmo não sendo consumidores frequentes, e poderia despertar um conhecimento subjetivo sobre cervejas. Ao mesmo tempo, surgiram recentemente no mercado brasileiro, cervejas especiais que apresentam características distintas dos produtos comerciais e, portanto, é razoável inferir que existam poucos consumidores especialistas neste segmento.

A partir dessa constatação, considera-se que o desenho de uma pesquisa abordando diferentes tipos de elicitação de preferências com um algoritmo de recomendação de cervejas especiais pode ser um cenário de investigação interessante que tem um potencial de despertar um engajamento maior dos participantes com o estudo. É possível que muitas pessoas se considerem conhecedores do tema e, assim, foi interessante investigar se a frequência de consumo e o conhecimento subjetivo podem influenciar a reação do indivíduo com as recomendações. A seguir, uma descrição de como o experimento foi estruturado.

Os estímulos do experimento foram processos de elicitação das preferências para cervejas especiais, apresentadas de cinco maneiras distintas, sendo que cada participante da pesquisa foi alocado aleatoriamente para cada estímulo. A primeira forma de elicitação de preferências é chamada "Histórico de Compras" em que o usuário indicou quais foram as últimas cervejas compradas ou consumidas de uma lista de cervejas comerciais de marcas conhecidas. É uma forma de obtenção das preferências, comumente utilizada em algoritmos de recomendação (RICCI; SHAPIRA; ROKACH, 2015). Dado que o indivíduo comprou as 
cervejas, é possível inferir que tais produtos ocupem posições altas em seu ranking de preferências, e, portanto, é um processo de elicitação de preferências por classificação/ranking (KNIJNENBURG; WILLEMSEN, 2015). O Apêndice A descreve este procedimento em detalhes.

A segunda forma de elicitação é chamada de "Características de Cerveja", em que foi apresentado um conjunto de qualidades das cervejas especiais, incluindo o tipo de sabor (leve, maltada), o grau de amargor (moderado, acentuado), a coloração (claro, escura), o aroma (frutada, floral), o teor alcóolico (abaixo de três graus, acima de cinco graus), a origem (Belga, Americana, entre outros) e o estilo da cerveja especial (Indian Ale Pale, American Ale Pale, entre outros). Este pode ser considerado um processo de elicitação de preferências baseado nos comentários dos indivíduos, conforme descrito por Knijnenburg e Willemsen (2015). O Apêndice B descreve este procedimento em detalhes.

A terceira forma de elicitação é chamada de "Características Pessoais" (Atitudes, Interesses e Opiniões) com perguntas sobre preferências não relacionadas diretamente com os atributos de uma cerveja especial como, por exemplo, tipos de restaurantes preferidos pelo indivíduo (churrascaria, comida japonesa, etc.), estilos preferidos de filmes (ação, romance, comédia, etc.), estilos de músicas preferidas (MPB, Sertanejo, Rock, etc.), esportes preferidos, viagem dos sonhos (Paris, Nova Iorque, Tailândia, etc.), cores preferidas e bebidas alcoólicas preferidas (Cerveja, Whisky, Vinho, etc.). Neste caso, este procedimento pode ser considerado como uma forma implícita do Processo de Elicitação de Preferências (KNIJNENBURG; WILLEMSEN, 2015). O Apêndice C descreve este procedimento em detalhes.

A quarta forma de elicitação é chamada de sugestões de preferências ao estilo "Tinder"” em que foram apresentadas dez sugestões de cervejas artesanais brasileiras com informações sobre sua origem, a cervejaria produtora, o estilo, o amargor, a aparência, os aromas da cerveja, a volumetria da embalagem, a coloração da bebida, a temperatura ideal para o consumo, o copo sugerido, o teor alcoólico e uma sugestão de harmonização com comidas. O indivíduo deveria simplesmente escolher se gostou ou não da sugestão. Esta forma de interação pode ser considerada como um processo de elicitação de preferências (PEP) por classificação em que o indivíduo indica de forma binária ( $\operatorname{sim}$ ou não) sua preferência. Ao mesmo tempo essa forma de elicitação pode ser considerada como uma tentativa de melhorar a assertividade da recomendação, provendo uma referência do tipo de produto a ser recomendado, como sugerido por Jugovac, Jannach e Dortmund (2017) na 
questão de melhorias quanto ao processo de elicitação. O Apêndice D descreve este procedimento em detalhes.

A quinta e última forma de elicitação na realidade não exigiu nenhuma interação, ou seja, o intuito foi não perguntar nenhuma informação de preferência de cerveja ou qualquer outro tema. Os indivíduos alocados nesse grupo viram somente uma mensagem que seriam direcionados para as recomendações de cervejas especiais, sem o questionamento de suas preferências, gostos ou necessidades. Este grupo pode ser considerado como o grupo de controle do experimento, chamado de "Controle". Ao mesmo tempo, este cenário pode ser considerado como uma situação de "cold start problem" (KNIJNENBURG; WILLEMSEN, 2015; NARA, 2019) em que o respondente é um novo usuário e não existem informações de preferências, sendo que o algoritmo informa as recomendações de cervejas especiais diretamente. O Apêndice E descreve este procedimento em detalhes.

\subsection{PROCEDIMENTOS}

A amostra da pesquisa foi composta por 485 adultos e o questionário desenvolvido na plataforma Qualtrics. No início do experimento, foi informado aos participantes que o objetivo da pesquisa era testar um sistema de recomendação de cervejas especiais baseado em inteligência artificial. Os exemplos de cervejas especiais tomaram como base produtos comercializados em um site de compra de cervejas especiais em funcionamento atualmente chamado Clube do Malte. Os participantes da pesquisa são pessoas que podem consumir bebidas alcoólicas e sem restrições a cervejas. Questionamentos sobre a frequência de consumo e o conhecimento subjetivo sobre cervejas especiais foram direcionados aos respondentes.

A etapa seguinte inicia com a manipulação do Processo de Elicitação das Preferências em que foram apresentadas randomicamente cinco diferentes interações aos participantes: Preferências baseadas em Compras Passadas, Preferências pelas Características da Cerveja, Características Pessoais (atitudes, interesses e opiniões), Sugestões de Preferências ao estilo "Tinder" e por último uma situação sem interação (grupo de controle), ou seja, não houve a solicitação das preferências do usuário. Os detalhes da forma de apresentação de cada grupo podem ser verificados nos apêndices deste estudo.

Após a manipulação do Processo de Elicitação de Preferências, foram apresentadas aleatoriamente dez recomendações de cervejas especiais de um conjunto de vinte e cinco produtos. Como incentivo ao maior engajamento dos participantes na pesquisa, seis 
respondentes foram sorteados para receberem três cervejas especiais indicadas por eles na intenção de compra. Os detalhes desta etapa estão no Apêndice F. Abaixo de cada recomendação, houve questionamentos sobre a semelhança da recomendação com o gosto do participante bem como sua intenção de compra da cerveja. Foi utilizada uma escala de 9 pontos $(1=$ certamente não compraria $/ 9=$ certamente compraria; $1=$ não tem nada a ver comigo $/ 9$ = tem tudo a ver comigo).

Após este processo em que o respondente avalia 10 cervejas especiais diferentes, o passo seguinte foi medir o grau de satisfação geral com o algoritmo de recomendação. Para tanto, os participantes responderam um conjunto de quatro perguntas em que foi usada uma escala Likert de 7 pontos. Estas são as duas variáveis dependentes: Preferência com a recomendação e Intenção de Compra. O Apêndice F descreve estes procedimentos.

A parte final da pesquisa consistiu na mensuração dos traços individuais dos participantes e seus dados demográficos.

\subsection{MEDIDAS}

O conhecimento subjetivo dos participantes da pesquisa sobre cervejas especiais foi realizado por meio de uma escala Likert de 7 pontos, tomando como base o estudo de Germann e Merkle (2020) que mediram o grau de conhecimento dos respondentes com a área da recomendação. Analogamente, Knijnenburg e Willemsen (2010) avaliaram o conhecimento dos pesquisados com o tema da recomendação.

A frequência de consumo de cervejas foi medida por uma escala de 7 pontos $(1=$ não costumo beber cerveja; $7=$ até mais de 12 vezes por mês). Pessoas com restrições ao consumo de cerveja foram direcionadas para o final da pesquisa.

Escalas Likert de 9 pontos foram usadas para medir o grau de semelhança percebido pelo indivíduo entre recomendação de cerveja e sua preferência, sua intenção de compra, bem como sua satisfação geral com o algoritmo de recomendação. As escalas foram baseadas em estudo de Gretzel e Fesenmaier (2005) e outros trabalhos relacionados com a adoção de recomendações (HARRIS; GOODE, 2008).

No caso das medições de traços individuais dos respondentes, escalas Likert de 7 pontos foram adaptadas para medir as seguintes características: Desejo de Controle, escala original de 20 itens, com base em pesquisas anteriores (BURGER; COOPER, 1979; FARAJIRAD; MELUMAD; JOHAR, 2017); Locus de Controle (LEVENSON, 1981), com foco no controle interno da escala original de 24 itens; Busca por Variedades, escala original de 5 
itens, levando em conta recentes estudos na área (OLSEN et al., 2015); Maximização, escala original de 13 itens, com base em trabalhos anteriores sobre maximizadores e satisfeitos (SCHWARTZ et al., 2002).

\subsection{ANÁLISE}

A amostra é composta por 485 respondentes sendo a maioria formada pelo público masculino $(65,9 \%)$ com formação superior $(90,5 \%)$. Os detalhes dos dados demográficos são apresentados nas tabelas abaixo.

\begin{tabular}{|c|c|}
\hline \multicolumn{2}{|c|}{ Quadro 2-Idade } \\
\hline Idade & Percentual \\
\hline 18 e 32 anos & $16,3 \%$ \\
\hline 33 e 47 anos & $57,3 \%$ \\
\hline 48 e 62 anos & $24,4 \%$ \\
\hline Acima de 63 anos & $1,9 \%$ \\
\hline
\end{tabular}

Fonte: Autor

\begin{tabular}{|l|c|}
\multicolumn{2}{c|}{ Quadro 3-Sexo } \\
\hline Sexo & Percentual \\
\hline Masculino & $65,9 \%$ \\
\hline Feminino & $34,1 \%$ \\
\hline
\end{tabular}

Fonte: Autor

Quadro 4 - Escolaridade

\begin{tabular}{|l|c|}
\hline Escolaridade & Percentual \\
\hline Ensino Médio & $4,4 \%$ \\
\hline Ensino Superior & $90,5 \%$ \\
\hline Pós-graduação & $4,0 \%$ \\
\hline Mestrado & $0,7 \%$ \\
\hline Doutorado & $0,4 \%$ \\
\hline
\end{tabular}

Fonte: Autor

Os resultados foram analisados por meio de análise de variância multivariada (MANOVA) usando os cinco grupos de processo de elicitação das preferências e as duas 
principais variáveis dependentes: Preferência e Intenção de Compra. A frequência de consumo da cerveja e o conhecimento subjetivo do indivíduo foram usados como covariáveis.

Figura 1 - Preferências e intenção de compra por tipo de elicitação inicial de preferências

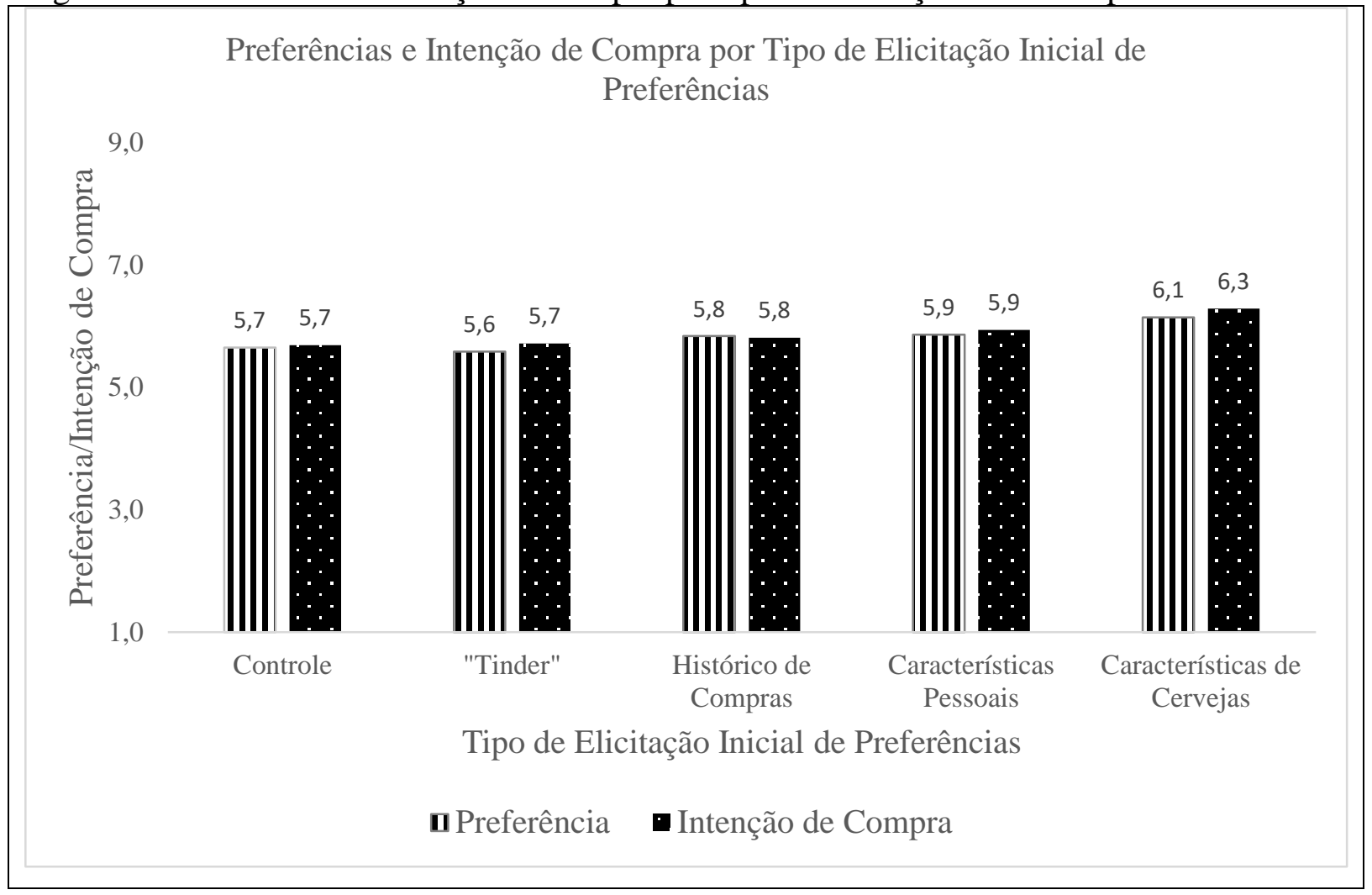

Fonte: Autor.

Uma vez que as mesmas cervejas foram apresentadas aleatoriamente a cada um dos respondentes, diferenças na preferência declarada e na intenção de compra só poderiam ser explicadas pelas diferenças nos procedimentos de elicitação de preferências iniciais. Uma MANOVA com 5 grupos sobre as variáveis dependentes Preferência e Intenção de Compra não revelou diferenças significativas para a variável dependente preferência $(F(4,480)=$ $1.86, \mathrm{p}=0,12)$ e uma diferença marginalmente significativa para a intenção de compra ( $\mathrm{F}(4$, $480)=2,22, p=0,07)$. A figura 1 apresenta os resultados de preferência e intenção de compra para cada um dos modos de elicitação.

Estudos anteriores identificaram que a aceitação das recomendações dos algoritmos pode depender do conhecimento do usuário sobre o tema da recomendação (KNIJNENBURG; REIJMER; WILLEMSEN, 2011; LOGG, 2017; YEOMANS et al., 2019). Para verificar se o conhecimento subjetivo teve efeito sobre a preferência e a intenção de compra identificadas neste estudo, o conhecimento subjetivo dos respondentes foi decodificado em 3 grupos (alto, médio e baixo conhecimento subjetivo). Em seguida, foi feita 
uma MANOVA 5 (correspondentes aos 5 tipos de elicitação inicial de preferências) x 3 (correspondentes aos 3 níveis de conhecimento subjetivo) sobre as duas variáveis dependentes (preferência e intenção de compra).

Os resultados revelaram um efeito principal do conhecimento subjetivo tanto para a variável dependente preferência $(\mathrm{F}(2,470)=26,76, \mathrm{p}<0,01)$ quanto para a variável dependente intenção de compra $(\mathrm{F}(2,470)=29,92$, p $<0,01)$ e um efeito principal marginalmente significativo do tipo de elicitação inicial para a variável dependente preferência $(\mathrm{F}(4,470)=2,15, \mathrm{p}=0,07)$ e significativo para a variável dependente intenção de compra $(\mathrm{F}(4,470)=2,76, \mathrm{p}<0,05)$. Não foram verificados efeitos significativos de interação entre o conhecimento subjetivo e o tipo de elicitação.

Testes post-hoc de Scheffé revelaram diferenças significativas $(\mathrm{p}<0,05)$ entre os grupos médio $(\mathrm{M}=6.4)$ e baixo conhecimento subjetivo $(\mathrm{M}=5.1)$ e alto e baixo conhecimento subjetivo $(\mathrm{M}=5.1)$ para a variável dependente preferência e diferenças significativas entre os grupos médio $(M=6.4)$ e baixo conhecimento subjetivo $(M=5.0)$ e alto $(\mathrm{M}=6.4)$ e baixo conhecimento subjetivo $(\mathrm{M}=5.0)$ para a variável dependente intenção de compra. Não foram verificadas diferenças significativas entre os grupos de médio e alto conhecimento subjetivo. Os testes post-hoc também sugerem diferenças significativas para as duas variáveis dependentes (preferência e intenção de compra) entre os grupos alto/médio e baixo para os tipos de elicitação inicial Características Pessoais e "Tinder". As Figuras 2 e 3 reportam os resultados obtidos para a preferência e intenção de compra de acordo com o tipo de elicitação inicial e grau de conhecimento subjetivo. 
Figura 2 - Preferências por tipo de elicitação inicial de preferências e por nível de conhecimento subjetivo

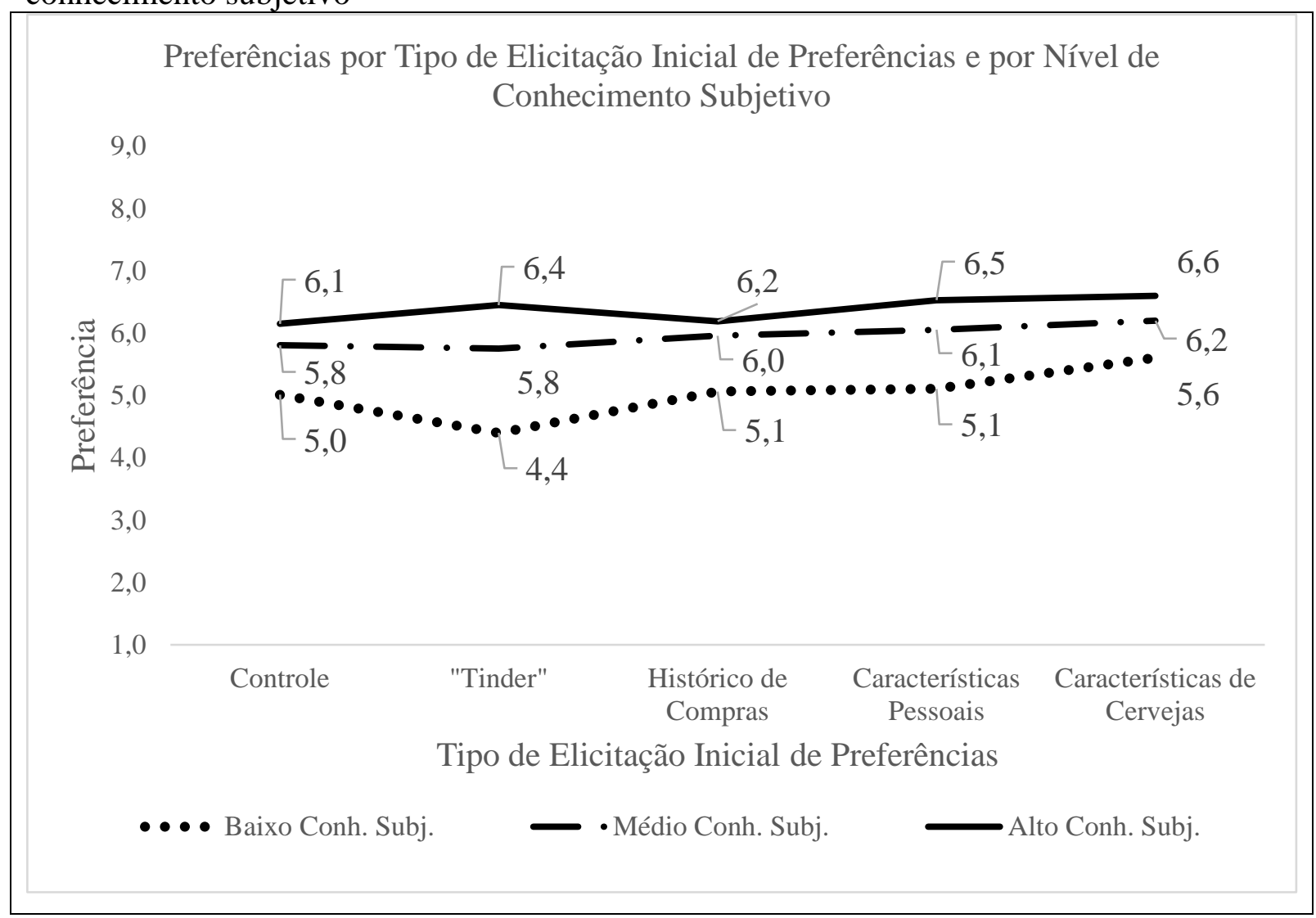

Fonte: Autor. 
Figura 3 - Preferência por tipo de elicitação inicial de preferências e por nivel de conhecimento subjetivo

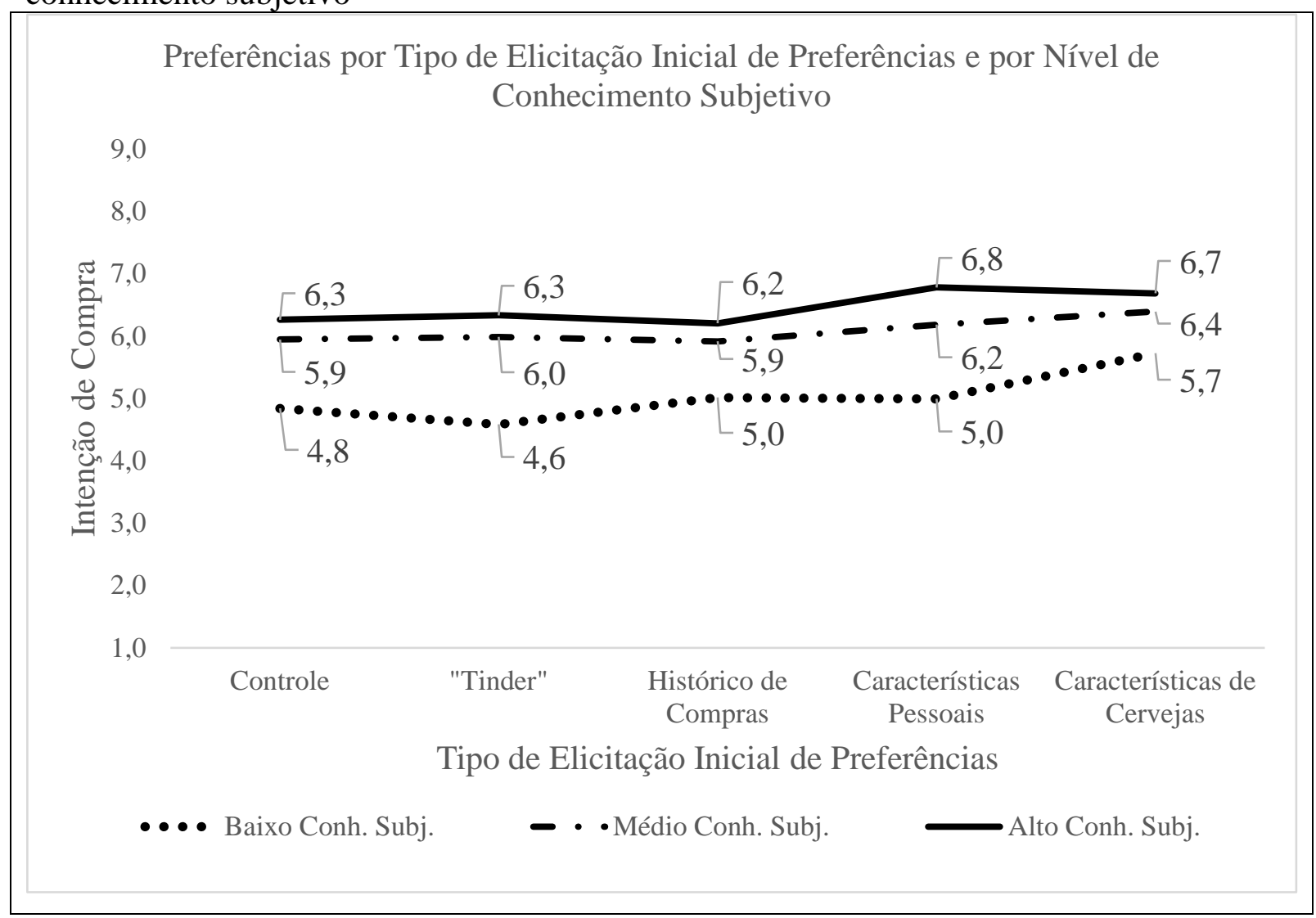

Fonte: Autor. 


\section{DISCUSSÃO E CONCLUSÃO}

A revisão da literatura indicou que a precisão (DIETVORST; SIMMONS; MASSEY, 2015a; GERMANN; MERKLE, 2020; YEOMANS et al., 2019), característica objetiva/subjetiva ou utilitária/hedônica da tarefa (CASTELO; BOS; LEHMANN, 2019; LOGG; MINSON; MOORE, 2019; LONGONI; CIAN, 2020) e o desconhecimento da lógica interna do algoritmo (DIETVORST; SIMMONS; MASSEY, 2015b; YEOMANS et al., 2019) são as principais linhas de alegações para a aceitação da recomendação. A revisão mostrou também que as lacunas encontradas apontam para o processo de elicitação de preferências (GRETZEL; FESENMAIER, 2005; KNIJNENBURG; REIJMER; WILLEMSEN, 2011; VERRUCK; NIQUE, 2017) e para a investigação da influência do conhecimento subjetivo sobre o domínio da recomendação (KNIJNENBURG; REIJMER; WILLEMSEN, 2011; LOGG, 2017).

Assim, esta pesquisa exploratória analisou a influência do processo de elicitação de preferências (PEP) na satisfação de recomendações para um produto com características subjetivas (cervejas especiais), examinou como o conhecimento sobre o domínio da recomendação interfere na satisfação do usuário e investigou novos traços individuais que pudessem afetar a satisfação. É possível dizer que esta pesquisa apresentou resultados satisfatórios tendo em vista a natureza exploratória do estudo e estabeleceu um diálogo com as pesquisas anteriores em vários aspectos.

O domínio avaliado neste estudo foi a cerveja especial, considerada um domínio subjetivo ou hedônico uma vez que cada indivíduo tem a sua preferência pessoal e passível de recusa pelos indivíduos. Porém, esta pesquisa exploratória comprovou que é possível a aceitação de recomendações de produtos com características subjetivas ou hedônicas, contrapondo estudos anteriores que indicaram a preferência por recomendações de pessoas (LOGG; MINSON; MOORE, 2019; LONGONI; CIAN, 2020; YEOMANS et al., 2019). Este estudo apontou que os indivíduos provavelmente aceitaram as recomendações de cervejas especiais na medida em que foi possível atribuir características comparativas entre as recomendações como, por exemplo, o grau de amargor, coloração, nível alcoólico, estilos, entre outras características e, dessa forma, quantificar uma recomendação subjetiva, aumentando as chances de aceitação (CASTELO; BOS; LEHMANN, 2019).

Pesquisadores concluíram que existe uma tendência da recomendação ser rejeitada quando o usuário não entende a lógica do algoritmo para a criação da recomendação 
(YEOMANS et al., 2019). Contudo, esta pesquisa demonstrou que provavelmente o PEP pode minimizar a dificuldade de compreender a lógica interna do algoritmo por meio de um fato curioso observado no experimento. Os participantes do grupo Características Pessoais ficaram satisfeitos com as recomendações dos produtos, apesar de responderem questionamentos e preferências totalmente aleatórias e sem nenhuma relação com o tema de cervejas especiais. Portanto o simples ato de transmitirem as preferências, independentemente de estarem relacionadas com o domínio da recomendação ou não, diminuiu a dificuldade de entendimento da lógica interna do algoritmo, pois a transmissão das preferências gerou uma percepção de relevância e transparência na recomendação, facilitando a sua aceitação (GRETZEL; FESENMAIER, 2005).

Outro grupo de pesquisadores indicaram que a satisfação com o processo de elicitação de preferências pode sofrer influência de traços individuais. Knijnenburg, Reijmer e Willemsen (2011) estudaram a maximização e busca por variedades como traços individuais, já outros pesquisadores apontaram que a falta de controle poderia ser um fator de insatisfação com a recomendação (HEGNER; BELDAD; BRUNSWICK, 2019; KNIJNENBURG; REIJMER; WILLEMSEN, 2011) ou que a sensação de maior controle potencializa a adoção do algoritmo de recomendação (TONG; HANCOCK; SLATCHER, 2016). Dessa forma, se tornou relevante a exploração de traços individuais não identificados em pesquisas anteriores.

Assim, foram analisadas como características pessoais Desejo de Controle (BURGER; COOPER, 1979; FARAJI-RAD; MELUMAD; JOHAR, 2017); Locus de Controle Interno (LEVENSON, 1981); Busca por Variedades (OLSEN et al., 2015) e Maximização (SCHWARTZ et al., 2002). Entretanto, não foi possível obter resultados significativos que comprovassem a influência de tais traços individuais nas variáveis dependentes. Outros pesquisadores também apontaram a ausência de traços individuais em seus trabalhos (ALEXANDER; BLINDER; ZAK, 2018; KRAMER et al., 2018). Portanto, é interessante o desenvolvimento de novos experimentos que possam descobrir outras características de personalidade relevantes para a satisfação com o processo de elicitação de preferências e com a recomendação.

Uma limitação deste trabalho se refere à amostra utilizada no experimento, uma vez que a pesquisa foi conduzida com um grupo de participantes e os resultados identificados não representam todo o país e, portanto, é interessante a replicação do experimento em outras regiões. Outra restrição está relacionada com a interface da plataforma Qualtrics criada para a manipulação dos processos de elicitação de preferências e execução do experimento. Ela poderia interferir nas respostas de preferências dos respondentes, mas tal influência não fez 
parte do escopo desta pesquisa. Assim como, a questão de familiaridade do indivíduo com recomendações de algoritmo, ou seja, com que frequência o usuário utiliza recomendações de algoritmos em sua decisões, situação que poderia apresentar alguma interferência na satisfação com a recomendação (ALEXANDER; BLINDER; ZAK, 2018).

Pesquisadores apontam a necessidade de novos estudos com o processo de elicitação de preferências (GRETZEL; FESENMAIER, 2005; JUGOVAC; JANNACH; DORTMUND, 2017; KNIJNENBURG; REIJMER; WILLEMSEN, 2011; VERRUCK; NIQUE, 2017) e esta pesquisa exploratória contribui para a literatura com a realização de um experimento inédito, diferentemente de estudos anteriores (GRETZEL; FESENMAIER, 2005; KNIJNENBURG; REIJMER; WILLEMSEN, 2011), trazendo novos temas para o diálogo. Esta pesquisa reuniu em um só experimento estudos sobre o processo de elicitação de preferências (PEP), o conhecimento subjetivo que o usuário possui sobre o domínio da recomendação e a recomendação de cervejas especiais, uma bebida alcoólica, ou seja, um produto com características subjetivas ou hedônicas. Portanto esta pesquisa colabora com novos conhecimentos para a literatura, mas ao mesmo tempo apresenta contribuições para a prática.

Com efeito, Longoni e Cian (2020) mencionam em seu artigo um fato curioso identificado pelo grupo de marketing do Walmart nos Estados Unidos. As bebidas alcoólicas e comidas são duas linhas de produtos sempre recomendadas no site do Walmart, mas raramente as recomendações são aceitas pelos consumidores. Os pesquisadores sugerem que bebidas alcóolicas e comida são produtos com características hedônicas e este fato poderia explicar a desconsideração pelas recomendações. Certamente seria necessária uma investigação mais detalhada dos motivos que causam as dificuldades de aceitação das recomendações de bebidas alcóolicas e comidas no site do Walmart, mas de todo modo, o presente trabalho de pesquisa poderia apontar caminhos para a resolução desse problema. Eventualmente outras empresas no mesmo segmento ou companhias com linhas de negócio similares poderiam enfrentar situações semelhantes.

Além disso, a pesquisa pode ajudar empresas ou desenvolvedores, demonstrando aspectos relevantes do comportamento do consumidor quando este interage com o algoritmo de recomendação e, assim, apresentar ideias para novas formas de elicitação de preferência que melhorem a experiência do usuário, aumentando sua satisfação com a recomendação dos produtos.

As empresas deveriam evitar a implementação de um processo de elicitação de preferências (PEP) que agrade todos ao mesmo tempo (“one-fits-all”) porque há níveis de conhecimento distintos entre as pessoas. Como observado, existem indivíduos considerados 
"novatos", com pouco conhecimento, ou "especialistas", pessoas com um nível de conhecimento elevado. Os resultados desta pesquisa mostraram que o conhecimento subjetivo do indivíduo sobre o domínio exerce uma influência na satisfação com a recomendação e, deste modo, o PEP poderia contribuir para identificar tal nível de conhecimento subjetivo já no estágio inicial de interação com o algoritmo e assim direcionar para a melhor forma de recomendação.

Jugovac, Jannach, Dortmund (2017) apontam que os desafios para o processo de elicitação de preferências (PEP) são: veracidade das preferências - as informações passadas pelo usuário devem representar a real necessidade da pessoa; assertividade do algoritmo - o algoritmo poderia indicar referencias, por exemplo apresentar o que seria um produto categorizado como três estrelas; engajamento do usuário - incentivar um engajamento maior do usuário no fornecimento da sua opinião; e novas formas de PEP.

O presente trabalho explorou a questão da assertividade do PEP (quarta manipulação de elicitação do experimento) em que foram sugeridas duas recomendações prévias como referências para o indivíduo. Não houve, no entanto, uma diferença significativa na satisfação da recomendação com essa forma de elicitação. Talvez seja necessária uma nova forma de manipulação para provocar um efeito.

Adicionalmente a revisão de literatura elaborada para o desenvolvimento desta pesquisa identificou pesquisas relevantes para o diálogo e pode ser considerada também como uma outra contribuição deste estudo, complementando o trabalho anterior de Verruck e Nique (2017).

Futuros trabalhos poderiam desenvolver novos experimentos envolvendo o PEP e o conhecimento prévio do usuário com o tema da recomendação para identificar novos efeitos com o processo de elicitação de preferências, especialmente trabalhar com os extremos do nível do conhecimento subjetivo, entre novatos que não conhecem nada sobre o assunto e especialistas, aqueles que se consideram conhecedores do domínio da recomendação. Concomitantemente novos trabalhos deveriam explorar outros traços individuais não estudados nesta pesquisa para que a descoberta de novas características psicológicas enriqueça a aprendizagem sobre o processo de elicitação de preferências.

Novos experimentos com o PEP em plataforma móveis ou utilizando técnicas de "Machine Learning", "Chabots" ou "Natural Language Processing" (JUGOVAC; JANNACH; DORTMUND, 2017), visando o engajamento do consumidor na transmissão de suas preferências seriam caminhos interessantes a serem desvendados. Com efeito, o uso de "Machine Learning" como um diálogo entre o algoritmo e o usuário poderão ser as novas 
formas de elicitação de preferências que promoverão melhor interação, exigirão poucos esforços dos usuários no fornecimento de suas preferências e poderão administrar a filtragem do nível de conhecimento do consumidor com o tema da recomendação.

É possível que a recomendação de algoritmo seja cada vez mais aceita pela sociedade (ALEXANDER; BLINDER; ZAK, 2018; KRAMER et al., 2018), independentemente do processo de elicitação de preferências (PEP), na medida em que o seu uso se apresenta cada vez mais visível para o público em geral, tornando o PEP uma interação natural e imperceptível para as pessoas. De todo modo, é esperado que esta pesquisa exploratória tenha proporcionado novos conhecimentos aos leitores e incentive o desenvolvimento de novas pesquisas para o enriquecimento da literatura bem com a prática de novas estratégias que melhorem a satisfação dos consumidores. 


\section{REFERÊNCIAS}

ALEXANDER, V.; BLINDER, C.; ZAK, P. J. Why trust an algorithm? Performance, cognition, and neurophysiology. Computers in Human Behavior, v. 89, p. 279-288, jul. 2018.

BURGER, J. M.; COOPER, H. M. The desirability of control. Motivation and Emotion, v. 3, n. 4, p. 381-393, 1979.

BURKE, R. Hybrid web recommender systems. In: BRUSILOVSKY, P.; KOBSA, A.; NEJDL, W. (Eds.). The adaptive web. 1st. ed. New York: Springer, Berlin, Heidelberg, 2007. v. 4, p. 377-408.

CASTELO, N.; BOS, M. W.; LEHMANN, D. R. Task-dependent algorithm aversion. Journal of Marketing Research, v. 56, n. 5, p. 809-825, 2019.

DIETVORST, B. J.; SIMMONS, J.; MASSEY, C. Understanding algorithm aversion: forecasters erroneously avoid algorithms after seeing them err. Academy of Management Proceedings, v. 2014, n. 1, p. 12227-12227, 2015 a.

DIETVORST, B.; SIMMONS, J. P.; MASSEY, C. Overcoming algorithm aversion: People will use imperfect algorithms if they can (even slightly) modify them. Management Science, v. 64 , n. 3, p. $1155-1170,2015$ b.

DOBRESCU, E.; DOBRESCU, E. M. The future of artificial intelligence in economics and management. Review of General Management, v. 26, n. 2, p. 82-89, 2017.

DOVE, J.; HILL, S. How to use Google Maps - navigating Google Maps. 2020. Disponível em: <https://www.digitaltrends.com/mobile/how-to-use-google-maps/>. Acesso em: 22 jun. 2020.

FARAJI-RAD, A.; MELUMAD, S.; JOHAR, G. V. Consumer desire for control as a barrier to new product adoption. Journal of Consumer Psychology, v. 27, n. 3, p. 347-354, 2017.

FELFERNIG, A. et al. Chapter 5 Constraint-Based Recommender Systems. In: RICCI, F.; ROKACH, L.; SHAPIRA, B. (Eds.). Recommender systems handbook. 2nd. ed. New York: Springer, Berlin, Heidelberg, 2015. p. 161-190.

GERMANN, M.; MERKLE, C. Algorithm Aversion in Delegated Investing SSRN Electronic Journal, p. 52, 2020. Disponível em: 〈https://www.ssrn.com/abstract=3364850>. Acesso em: 23 jul. 2020.

GRETZEL, U.; FESENMAIER, D. R. Persuasiveness of preference elicitation processes in destination recommendation systems department of recreation, park and tourism sciences National Laboratory for Tourism and e Commerce Persuasion through preference elicitation. Information Technology \& Tourismnformation and Communication Technologies in Tourism 2005, n. 2003, p. 194-204, 2005.

HARRIS, L. C.; GOODE, M. M. H. Online service scapes, trust, and purchase intentions. Journal of Services Marketing, v. 24, n. 3, p. 230-243, 2008. 
HEGNER, S. M.; BELDAD, A. D.; BRUNSWICK, G. J. In Automatic we trust: investigating the impact of trust, control, personality characteristics, and extrinsic and intrinsic motivations on the acceptance of autonomous vehicles. International Journal of Human-Computer Interaction, v. 35, n. 19, p. 1769-1780, 2019.

HOFFMAN, D. L.; NOVAK, T. P. Consumer and object experience in the internet of things: An assemblage theory approach. Journal of Consumer Research, v. 44, n. 6, p. 1178-1204, 2018.

HOSANAGAR, K. A Human guide's to machine intelligence: how algorithms are shaping our lives and hoe we can stay in control. 1st. ed. New York: Penguin, 2019.

JUGOVAC, M.; JANNACH, D.; DORTMUND, T. Interacting with recommendersoverview and research. ACM Transactions on Interactive Intelligent Systems (TiiS), v. 7, n. 3, p. 10, 2017.

KNIJNENBURG, B. P.; REIJMER, N. J. M.; WILLEMSEN, M. C. Each to his own: how different users call for different interaction methods in recommender systems. In: RECSYS'11 - PROCEEDINGS OF THE 5TH ACM CONFERENCE ON RECOMMENDER SYSTEMS. Anais... Chicago: ACM, 2011.

KNIJNENBURG, B. P.; WILLEMSEN, M. C. The effect of preference elicitation methods on the user experience of a recommender system. In: CONFERENCE ON HUMAN FACTORS IN COMPUTING SYSTEMS - PROCEEDINGS. Anais...New York: ACM, 2010

KNIJNENBURG, B. P.; WILLEMSEN, M. C. Chapter 9 Evaluating Recommender Systems with User Experiments. In: RICCI, F.; ROKACH, L.; SHAPIRA, B. (Eds.). Recommender Systems Handbook. 2nd. ed. New York: Springer, Berlin, Heidelberg, 2015. p. 315-316.

KRAMER, M. F. et al. When do people want AI to make decisions? In: AIES 2018 PROCEEDINGS OF THE 2018 AAAI/ACM CONFERENCE ON AI, ETHICS, AND SOCIETY. Anais...New Orleans: AAAI/ACM, 2018.

LAPORTA, T. Brasil é o 10o. maior mercado de vodca, a bebida 'anfitriã' da Copa. Portal G1, 30 jun. 2018. Disponível em: <https://g1.globo.com/economia/noticia/brasil-e-o-10maior-mercado-de-vodca-a-bebida-anfitria-da-copa.ghtml>. Acesso em: 20 nov. 2020.

LEVENSON, H. Differentiating among powerful others, internality and chance. In: LEFCOURT, H. M. (Ed.). Research with the locus of control construct. 1st ed. New York: Academic Press, 1981. p. 15-63.

LOGG, J. Theory of machine: when do people rely on algorithms? Harvard Business School Working Paper, n. 17-086, March 2017.

LOGG, J. M.; MINSON, J. A.; MOORE, D. A. Algorithm appreciation: people prefer algorithmic to human judgment. Organizational Behavior and Human Decision Processes, v. 151, p. 90-103, 2019. 
LONGONI, C.; CIAN, L. Artificial intelligence in utilitarian vs. hedonic contexts: the "Wordof-Machine" effect. Journal of Marketing, p. 1-18, Nov. 2020.

MARR, B. What is the difference between artificial intelligence and machine learning? 2016. Disponível em: <https://www.forbes.com/sites/bernardmarr/2016/12/06/what-is-thedifference-between-artificial-intelligence-and-machine-learning/\#153331422742, 2016>. Acesso em: 7 jun. 2019.

MCCAFFREY, M. et al. Consumer intelligence series: prepare for the voice revolution PricewaterhouseCoopers. [s.1.] PricewaterhouseCoopers, 2018.

NARA, R. Algoritmos de recomendação: o que são e como implementá-los? 2019.

Disponível em: <https://blog.geekhunter.com.br/algoritmos-de-recomendacao-o-que-sao-ecomo-implementa-los/>. 2019. Acesso em: 13 jun. 2019.

NING, X.; DESROSIERS, C.; KARYPIS, G. Chapter 2: A comprehensive survey of neighborhood-based recommendation methods. In: RICCI, F.; ROKACH, L.; SHAPIRA, B. (Eds.). Recommender systems handbook. 2nd. ed. New York: Springer, Berlin, Heidelberg, 2015. p. 37-76.

OLSEN, S. O. et al. Differences and similarities between impulsive buying nad variety seeking: a personality-based perspective. Psychology \& Marketing, v. 33, n. 1, p. 36-47, 2015 .

PARK, D. H. et al. A literature review and classification of recommender systems research. Expert Systems with Applications, v. 39, n. 11, p. 10059-10072, 2012.

PERWEJ, Y. et al. The Internet of Things (IoT) and its application domains. International Journal of Computer Applications, v. 182, p. 36-49, 2019.

PORTUGAL, I.; ALENCAR, P.; COWAN, D. The use of machine learning algorithms in recommender systems: a systematic review. Expert Systems with Applications, v. 97, n. 1, p. 205-277, 2018.

PRATA, M. Conheça o incrível mercado das casas conectadas. Brazil Programa Mundo S/A, Globosat, 2019. Disponível em:

<https://globosatplay.globo.com/globonews/v/7682804/>. Acesso em: 17 jun. 2019.

RICCI, F.; SHAPIRA, B.; ROKACH, L. Chapter 1 recommender systems: introduction and challenges. In: RICCI, F.; ROKACH, L.; SHAPIRA, B. (Eds.). Recommender systems handbook. 2nd ed. New York: Springer, 2015. p. 1-34.

ROOSEVELT, T. Citizenship in a Republic: discurso na Universidade de Sorbonne, França, 1910. 2021. Disponível em:

<https://www.theodoreroosevelt.org/content.aspx?page_id=22\&club_id=991271\&module_id =339333>. Acesso em: 02 fev. 2021 .

SCHWARTZ, B. et al. Maximizing versus satisficing: happiness is a matter of choice. Journal of Personality and Social Psychology, v. 83, n. 5, p. 1178-1197, 2002. 
TONG, S. T.; HANCOCK, J. T.; SLATCHER, R. B. Online dating system design and relational decision making: choice, algorithms, and control. Personal Relationships, v. 23, n. 4, p. 645-662, 2016.

VERRUCK, F.; NIQUE, M. W. The behavioral side of recommendation agents: a bibliometric review O Lado Comportamental dos Agentes de Recomendação: Uma Revisão Bibliométrica. Brazilian Journal of Management \& Innovation, v. 5, n. 1, p. 101-124, 2017.

XIAO, B.; BENBASAT, I. An empirical examination of the influence of biased personalized product recommendations on consumers' decision making outcomes. Decision Support Systems, v. 110, p. 46-57, jun. 2018.

YEOMANS, M. et al. Making sense of recommendations. Journal of Behavioral Decision Making, v. 32, n. 4, p. 403-414, 2019. 
APÊEDICE A - Grupo I - Histórico de compras 
O sistema de recomendações que estamos testando está baseado no histórico de compras de cervejas do consumidor. Como não conhecemos o seu histórico de compras e consumo, gostaríamos de saber as marcas de cerveja que você já comprou ou bebeu. Entre as cervejas abaixo, indique todas aquelas que você comprou ou bebeu no último ano.

\begin{tabular}{|c|c|c|c|c|}
\hline$\square$ Amistel & $\square$ Carlsberg & $\square$ Estrella Galicia & $\square$ Leffe & $\square$ Quilmes \\
\hline$\square$ Antartica & $\square$ Colorado & $\square$ Fax & $\square$ Miller & $\square$ Schin \\
\hline$\square$ Bavaria & $\square$ Corona & $\square$ Guinness & $\square$ Norteña & $\square$ Serra Malte \\
\hline$\square$ Black Princess & $\square$ Devassa & $\square$ Heineken & $\square$ Original & $\square$ Skol \\
\hline$\square$ Bohemia & $\square$ Dos Equis (XX) & $\square$ Hoegaarden & $\square$ Paulaner & $\square$ sol \\
\hline Brahma & $\square$ Duvel & $\square$ Insana & $\square$ Paulistânia & $\square$ Stella Artois \\
\hline$\square$ Budweiser & $\square$ Eisenbahn & $\square$ Itaipava & $\square$ Petra & $\square$ Vedett \\
\hline Baden-Baden & $\square$ Erdinger & $\square$ Kaiser & $\square$ Polar & $\square$ Warsteiner \\
\hline
\end{tabular}


APÊNDICE B - Grupo II - Características de cerveja 
O sistema de recomendações que estamos testando está baseado nas preferências do consumidor sobre cervejas. Como não conhecemos as suas preferências, gostaríamos de fazer algumas perguntas. Vamos lá?

Que estilo(s) de cerveja você prefere?

$\square$ Leve

Maltada

Lupulada

Torrada

Que nível de amargor de cerveja você prefere?

$$
\text { Leve }
$$

Que tipo de coloração de cerveja você prefere?

Claro (Por exemplo, Pilsen)

○
Médio (por exemplo, Ale)

○

Moderado

Alcóolica

Complexa

Frutada

Qualquer estilo
Acentuado
Escura (por exemplo, Dark Ale)

O
Todos

O

Que tipo de aroma você prefere na cerveja?

Frutada

Citrica

$\square$

Que teor alcóolico de cerveja você prefere?

Abaixo de 39

O
Entre $3 \%$ a $5 \%$

0
Acima de $5 \%$

O
Quanto mais melhor

O

Que tipo de escola cervejeira você prefere?

Belga

Americana 
Qual(is) do(s) estilo(s) de cerveja abaixo você já experimentou?

$\begin{array}{llll}\square \text { Pilsen } & \square \text { IPA (Indian Pale Ale) } & \square \text { Stout } & \square \text { Old Ale } \\ \square \text { Weiss } & \square \text { APA (American Pale Ale) } & \square \text { Porter } & \square \text { Sour Ale } \\ \square \text { Witbier } & \square \text { English Pale Ale } & \square \text { Dunkel } & \square \text { Saison } \\ \square \text { Red Ale } & \square \text { Dark Lager } & \square \text { Tripel } & \square \text { Fruit Beer } \\ \square \text { Bock } & \square \text { Weizen } & \square \text { Barley Wine } & \square \text { Belgian Pale Ale }\end{array}$


APÊNDICE C - Grupo III - características pessoais 
O sistema de recomendações que estamos testando está baseado no conhecimento das preferências do consumidor sobre esportes, atividades culturais e gastronômicas. Como não conhecemos as suas preferências, gostaríamos de fazer algumas perguntas. Vamos lá?

Qual(is) do(s) tipo(s) de restaurante abaixo você prefere?
$\square$ Churrascaria
$\square$ Brasileira
Frutos do Mar
Comida Japonesa
$\square$ Alemã
$\square$ Moderna
$\square$ Italiana
$\square$ Saudável
$\square$ Todos. Adoro comer.
$\square$ Vegetariana
$\square$ Árabe

Qual(is) estilo(s) de filme você prefere assistir?
$\square$ Ação
Documentários
Romance
Ficção Científica
Comédia
Nenhum. Não gosto de assitir filmes.
Drama
Todos. Adoro filmes.

Qual(is) estilo(s) de música você prefere?
$\square$ MPB
$\square$ Clássica
$\square$ Funk
$\square$ Sertanejo
$\square$ Jazz
$\square$ Hip Hop
$\square$ Eletrônica
$\square$ Pop Internacional
$\square$ Heavy Metal
$\square$ Rock
$\checkmark$ Samba
$\square$ Nenhuma. Não gosto de ouvir música.
$\square$ Pagode
$\square$ Gospel

Qual(is) seu(s) esporte(s) preferido(s)?
$\square$ Futebol
$\square$ Golfe
Beisebol
$\square$ Basquete
$\square$ Futebol americano
$\square$ Hóquei
$\square$ Voleibol
$\square$ Squash
Criquete
Tênis
$\square$ Rugby
$\square$ Nenhum. Não gosto de esportes. 
Qual(is) a(s) viagem(ns) dos seus sonhos?

$\begin{array}{ll}\square \text { Paris } & \square \text { Bora Bora } \\ \square \text { Nova Iorque } & \square \text { Moscou } \\ \square \text { Londres } & \square \text { Toronto } \\ \square \text { Istambul } & \square \text { Honolulu } \\ \square \text { Cairo } & \square \text { Taiti }\end{array}$

\section{Que cor(es) você prefere?}

$\begin{array}{ll}\square \text { Amarelo } & \square \text { Preto } \\ \square \text { Azul } & \square \text { Rosa } \\ \square \text { Vermelho } & \square \text { Verde } \\ \square \text { Roxo } & \end{array}$

$\square$ Rum

$\square$ Champanhe

$\square$ Whisky

$\square$ Vinho
$\square$ Gim
$\square$ Cachaça
$\square$ Vodka

Qual(is) as suas bebidas alcóolicas preferidas?

$\begin{array}{lll}\square \text { Cerveja } & \square \text { Cachaça } & \square \text { Rum } \\ \square \text { Whisky } & \square \text { Gim } & \square \text { Champanhe } \\ \square \text { Vinho } & \square \text { Vodka } & \square \text { Tequila }\end{array}$


APÊNDICE D - Grupo IV - solicitação de preferências ao estilo "Tinder" 
Os participantes que forem destinados a este grupo verão sugestões de dez cervejas artesanais e deverão indicar se gostaram ou não da sugestão conforme abaixo. As cervejas apresentadas neste grupo são diferentes das recomendações de cervejas em termos de volumetria da embalagem, marca ou cervejaria:

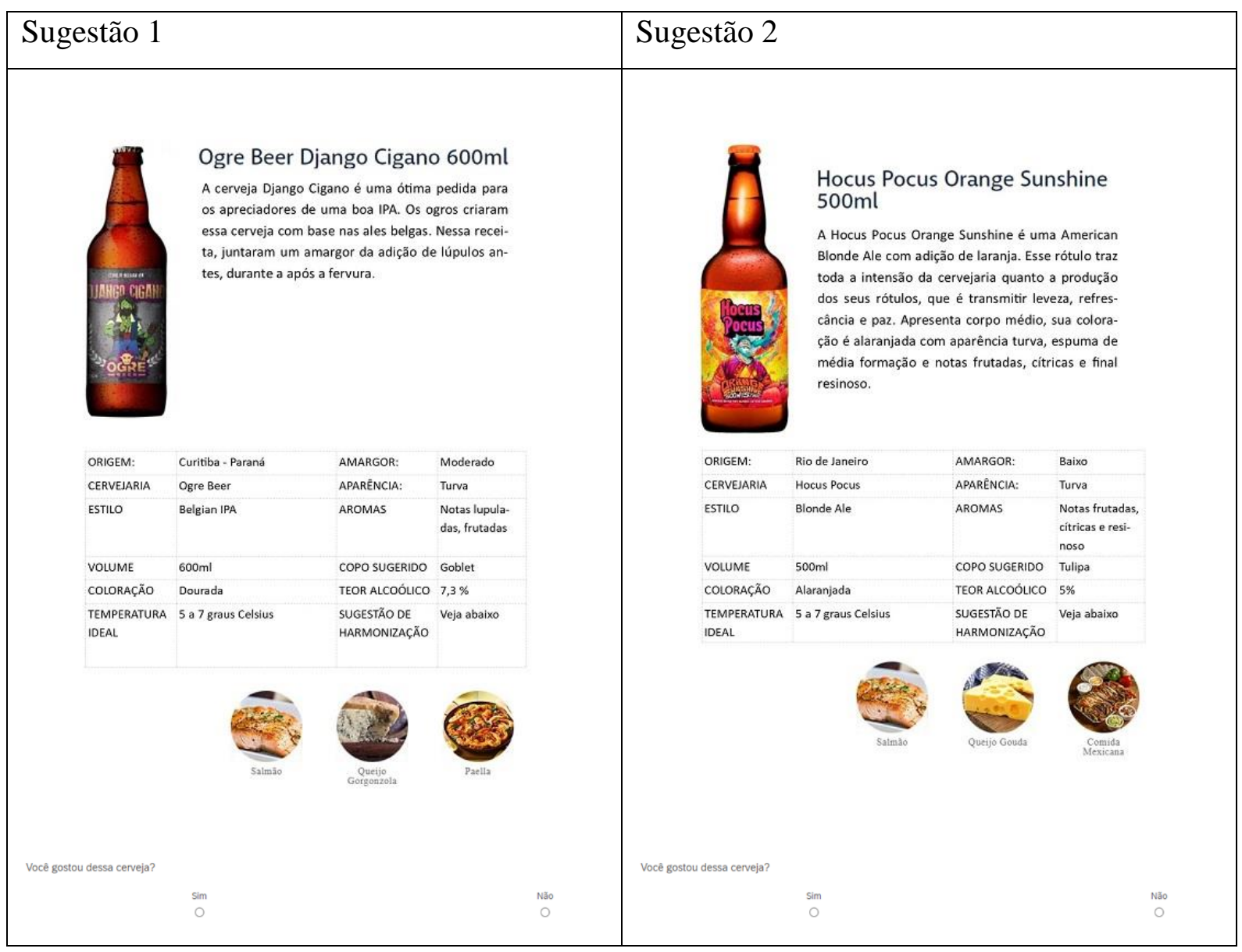




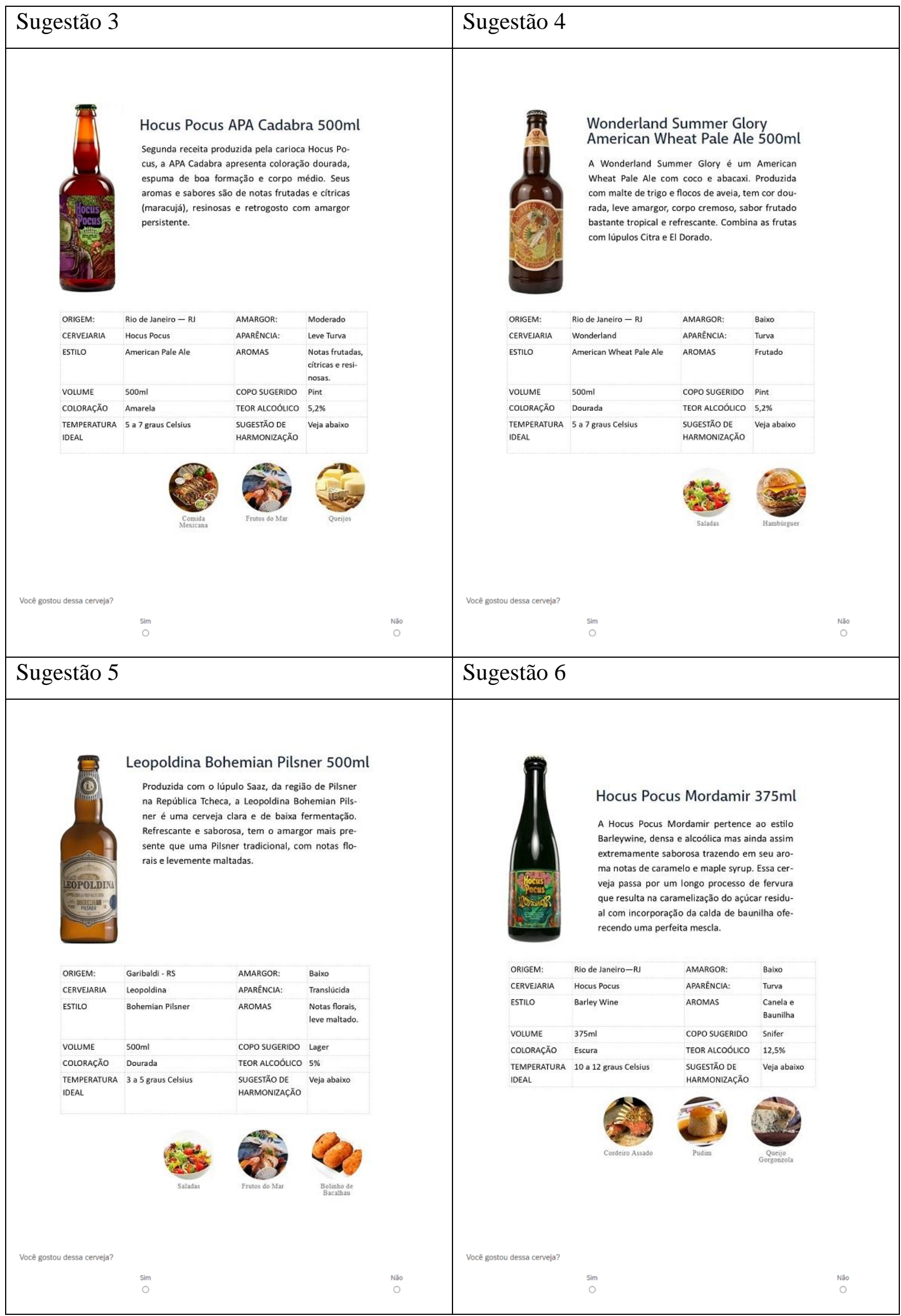




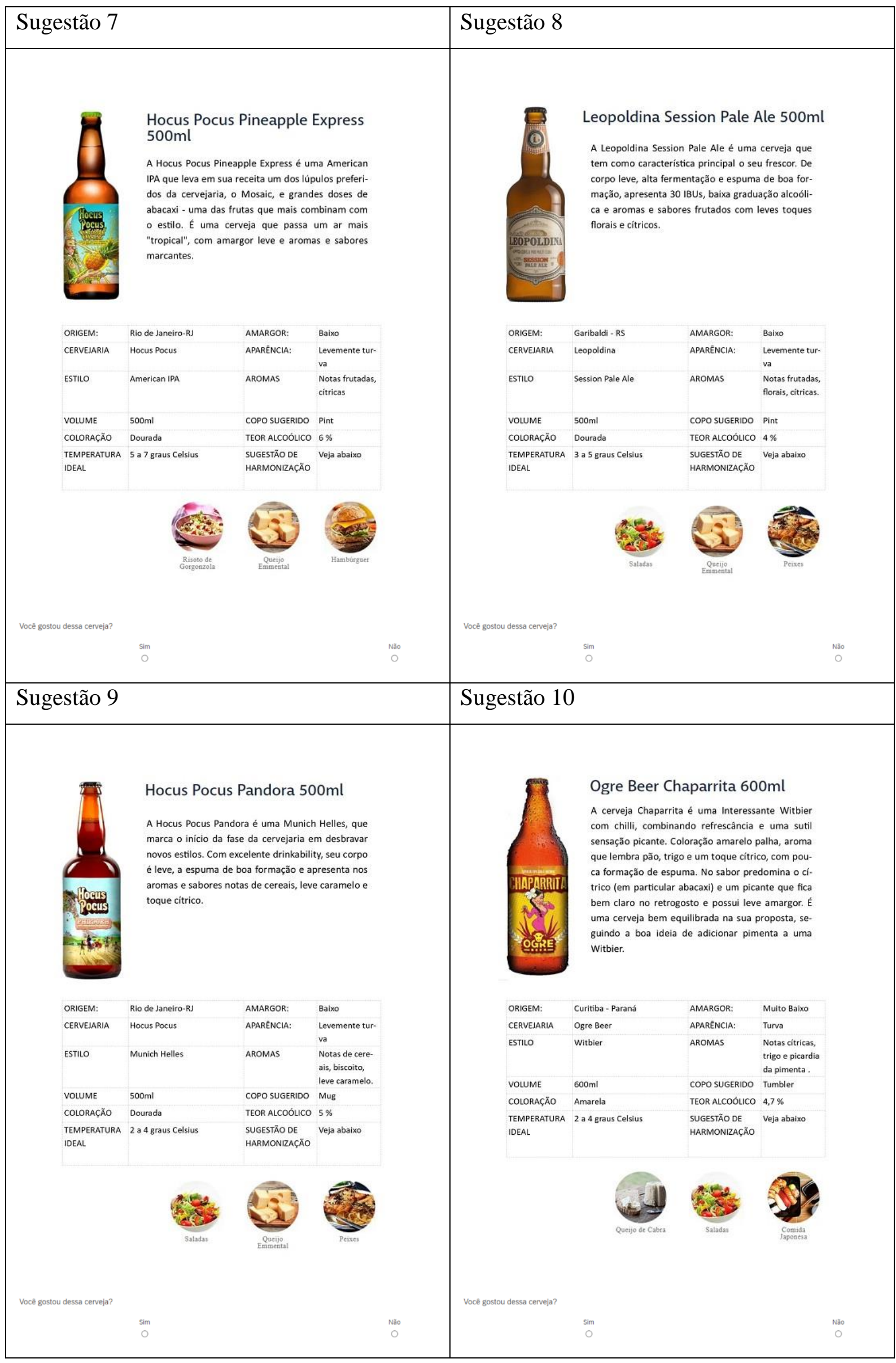


APÊNDICE E - Grupo V - Controle (sem interação) 
Não haverá nenhuma solicitação de preferência neste grupo. Será apresentado somente um texto informando que serão apresentadas as recomendações de cervejas artesanais conforme abaixo:

O sistema de recomendações fará algumas sugestões de cervejas especiais a você. 
APÊNDICE F - Tela que informa o início da recomendação e a explicação do sorteio de cervejas especiais 
A partir deste momento o sistema de Inteligência Artificial vai identificar 10 cervejas especiais especialmente recomendadas para você. Elas serão apresentadas de acordo com as suas preferências na ordem identificada pelo Sistema de Inteligência Artificial que estamos testando. Tudo que você tem a fazer é atribuir uma nota para cada recomendação de acordo com o grau de adequação às suas preferências. Em seguida indique também qual é a probabilidade de você a comprar a cerveja recomendada.

Seis (6) respondentes desta pesquisa concorrerão a um sorteio de três (3) garrafas de 1 tipo de cerveja especial. A cerveja que o sorteado ganhará será escolhida dentre aquelas que o respondente indicou que mais gostaria de comprar.

Após o texto acima, será introduzido uma animação GIF com intuito de simular o cálculo das recomendações pelo algoritmo e assim apresentar uma situação mais próxima a realidade.

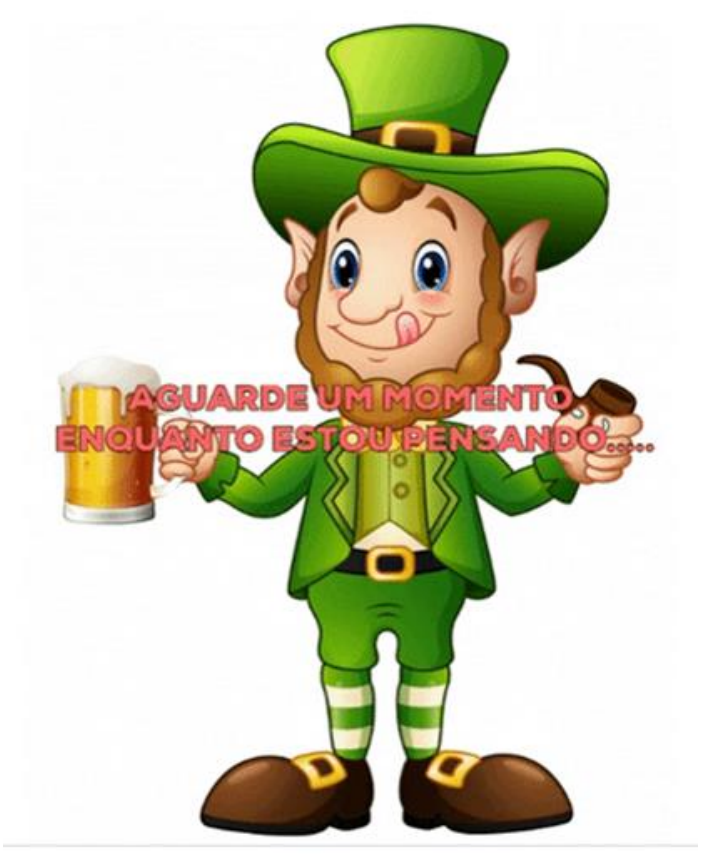

A seguir a lista das vinte cinco cervejas artesanais que farão parte da "base de dados" do algoritmo de recomendação que serão randomizadas. Somente dez cervejas serão apresentadas aleatoriamente para cada participante da pesquisa como recomendações originadas pelo algoritmo. 


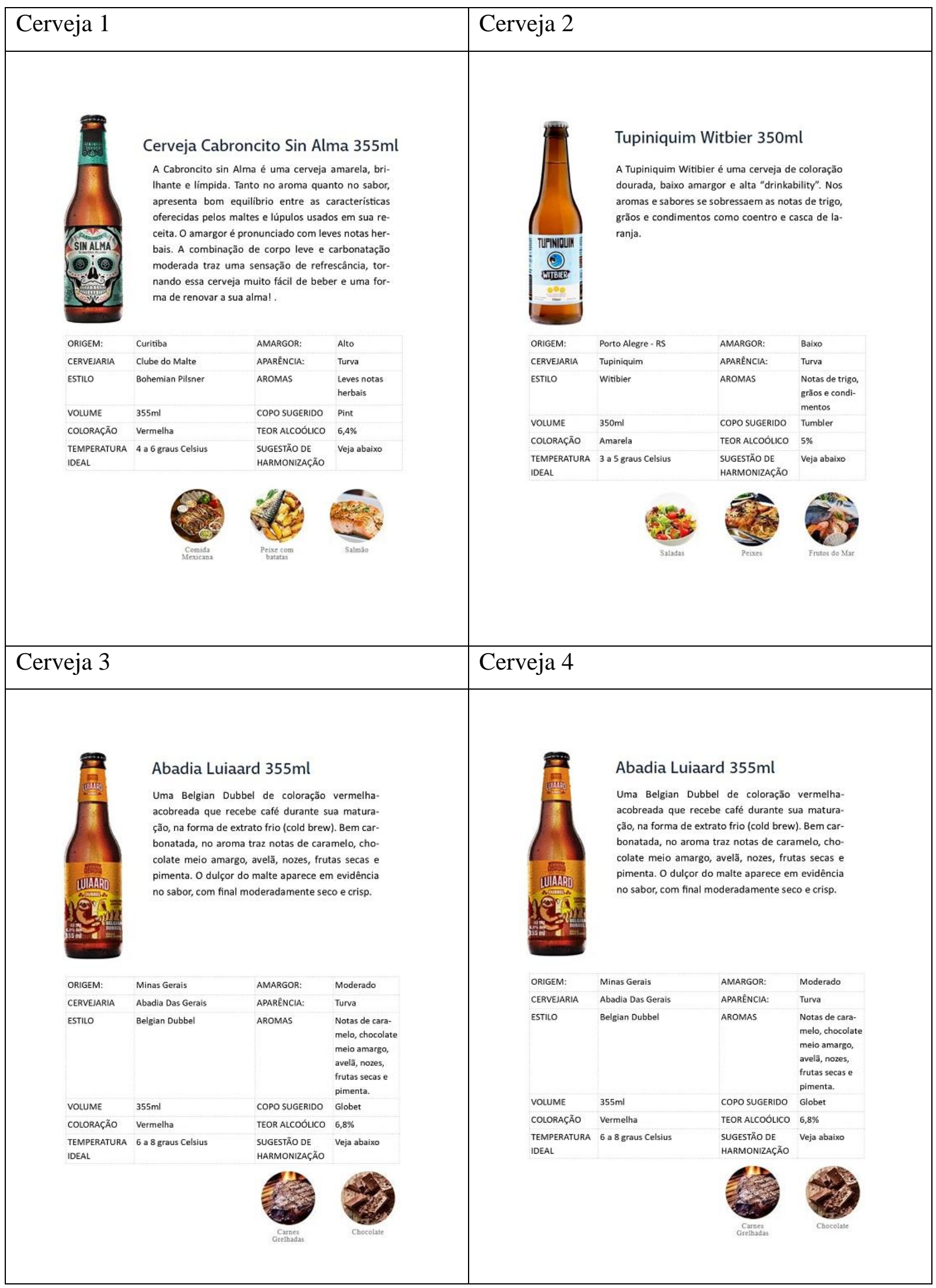




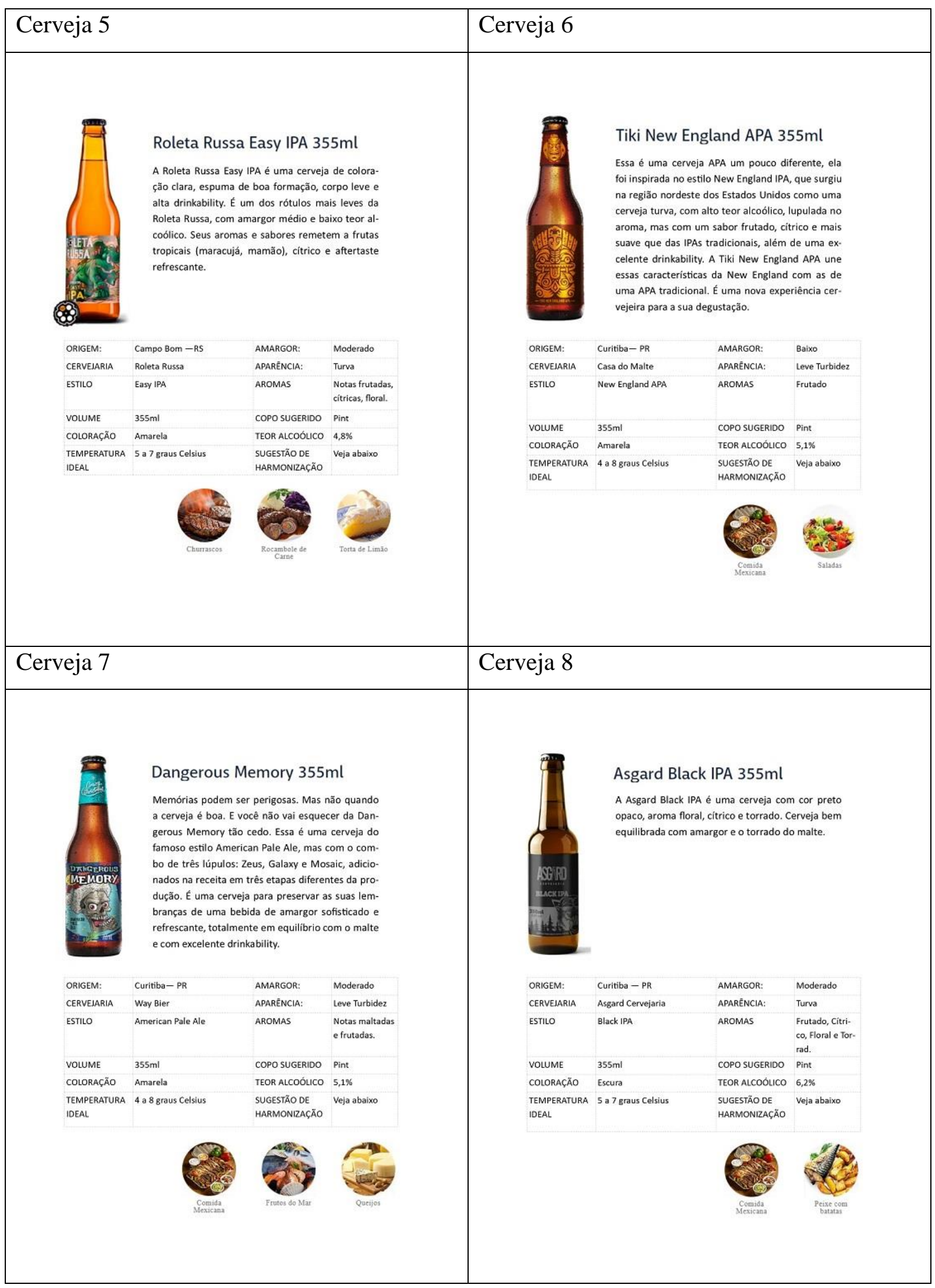




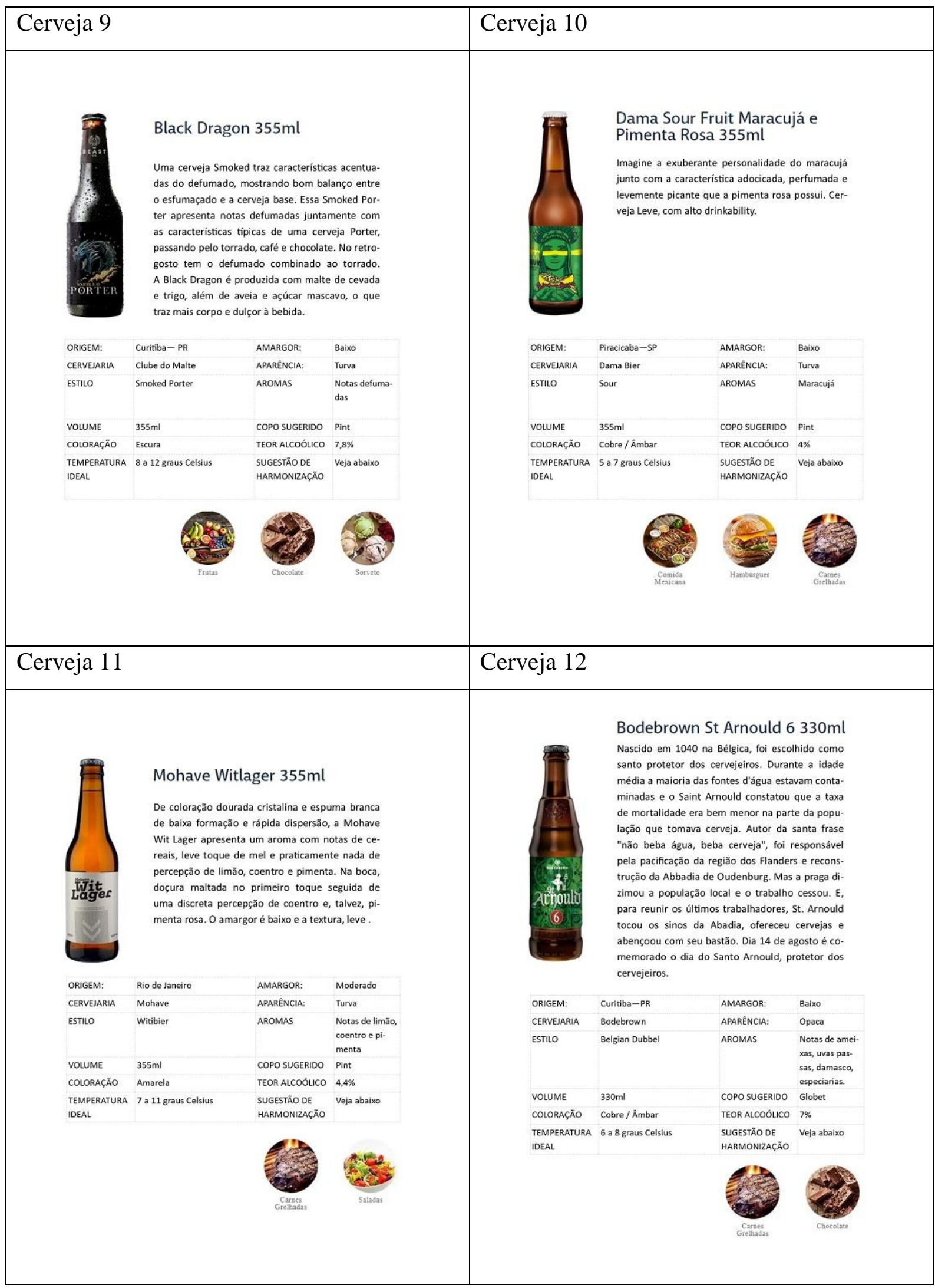




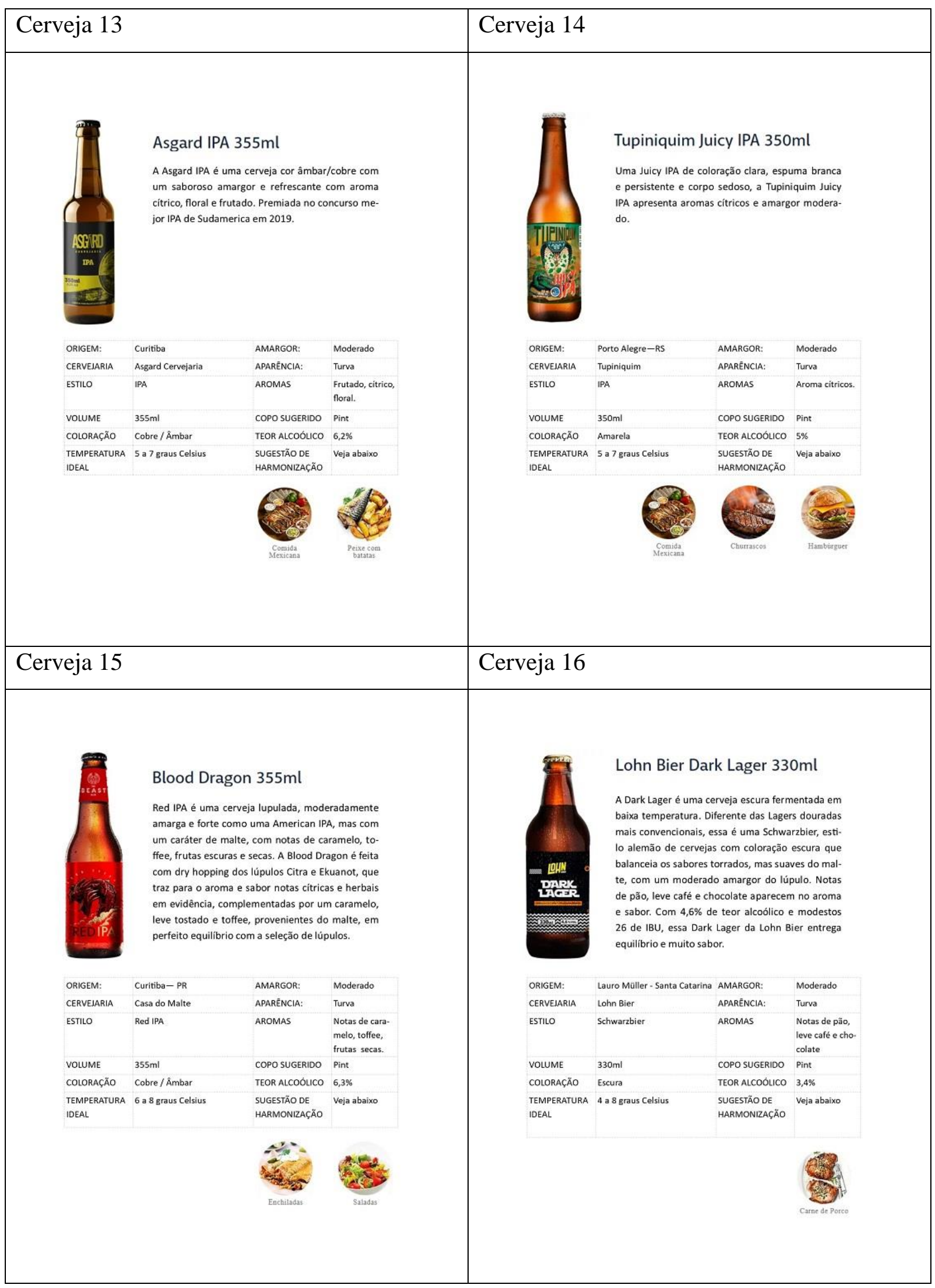




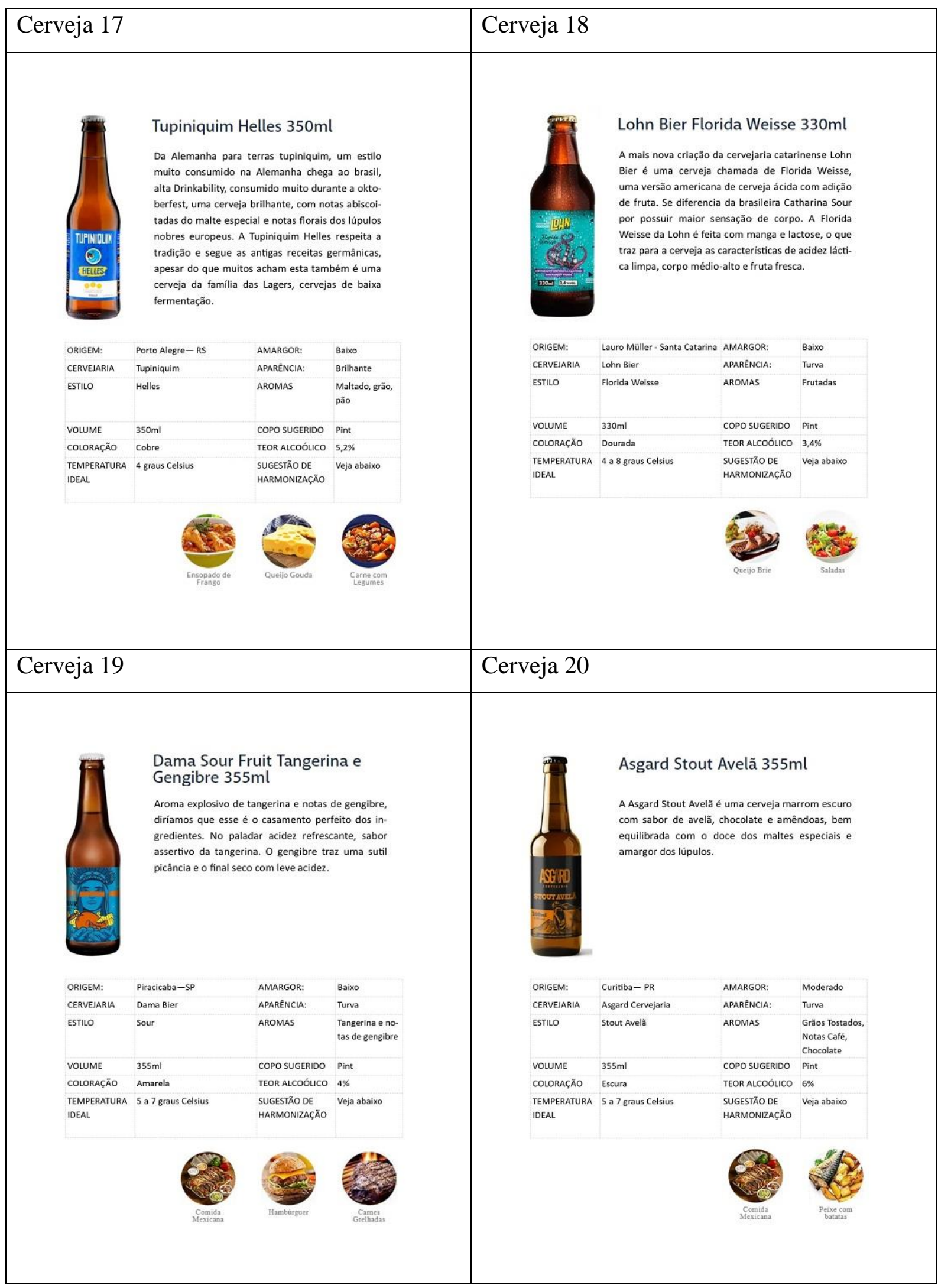




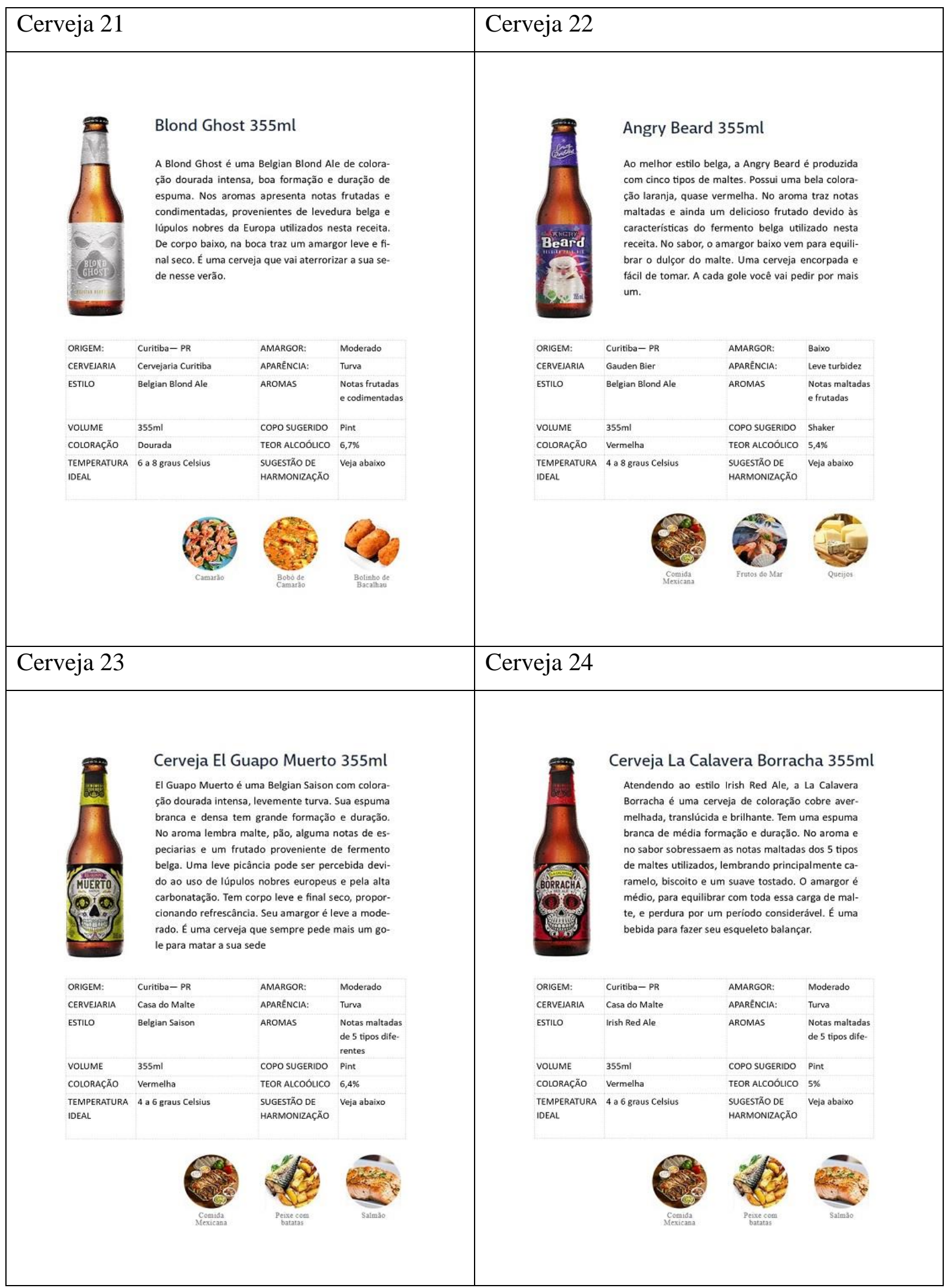




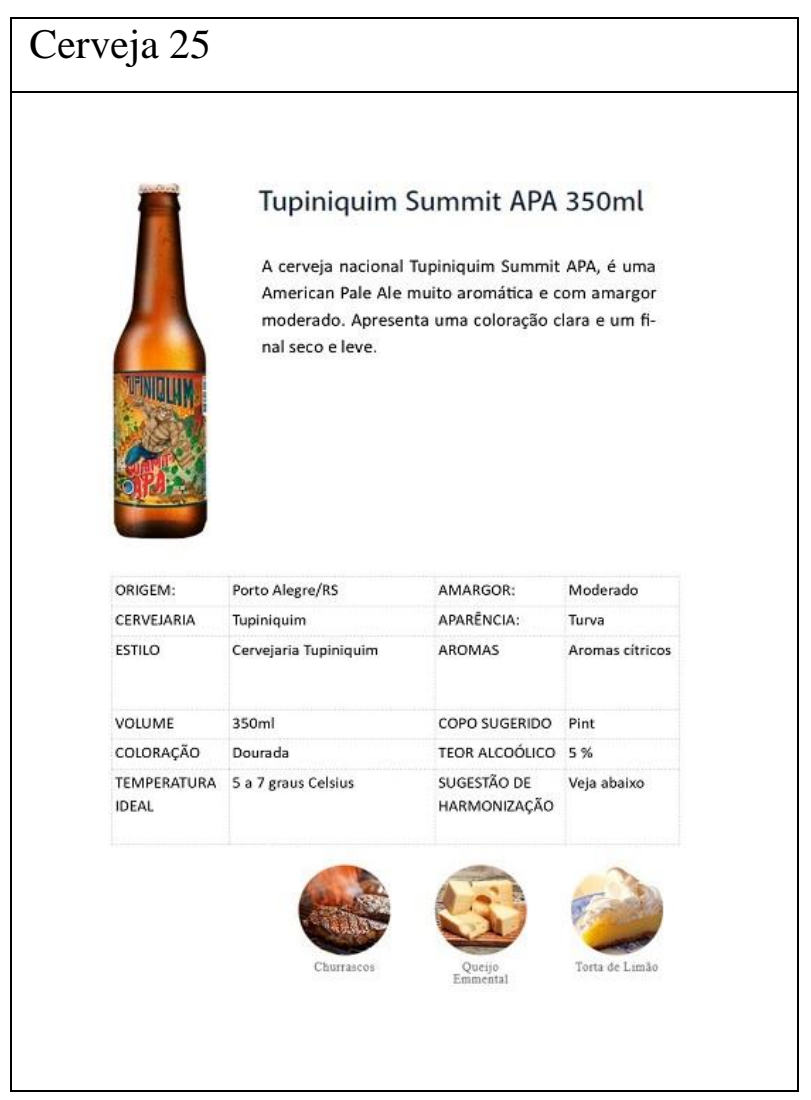

